\title{
Development of Replacements for Phoscoating Used in Forging, Extrusion and Metal Forming Processes Final Report
}

\author{
Prepared under NCMS Project Number 140168 \\ and DOE Agreement Number DE-FC07-94CE41123
}

Compiled by

National Center for Manufacturing Sciences

3025 Boardwalk

Ann Arbor, Michigan 48108-3266

March 2003 


\section{(c)2003 National Center for Manufacturing Sciences, Inc.}

This report was prepared by the National Center for Manufacturing Sciences (NCMS) as an account of work sponsored by NCMS on behalf of the Department of Energy Office of Industrial Technologies (DOE OIT).The information in this document is proprietary to NCMS. It is protected both under the U.S. Copyright Act and applicable state trade secret laws and may not be reproduced or disseminated without the express written permission of NCMS. Neither NCMS, members of NCMS, nor any person acting on behalf of them:

- makes any warranty or representation, express or implied, with respect to the accuracy, completeness or usefulness of the information contained in this report, or that the use of any information, apparatus, method, or process disclosed in this report will not infringe privately-owned rights, or

- assumes any liability with respect to the use of, or from damages resulting from the use of, any information, apparatus, method, or process disclosed in this report.

This effort is sponsored by the Department of Energy;.

This document contains information developed through the support of the Department of Energy under Agreement No. DE-FC07-94CE41123 and the content of the information does not necessarily reflect the position or policy of the Government; no official endorsement should be inferred. The Government has certain rights in the information and may publish, distribute, translate, duplicate, exhibit and perform such Copyrighted work for Governmental purposes only. 


\section{Table of Contents}

Section

List of Figures . $\mathrm{V}$

List of Tables vii

Acronyms and Abbreviations viii

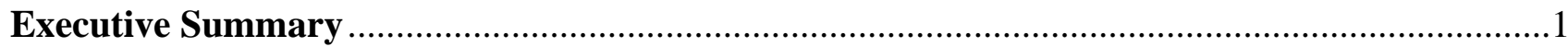

Survey of Coatings and Surface Modification Processes for Cold Forging Tooling ..................4

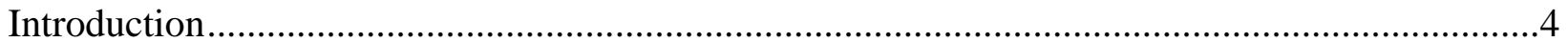

Candidate Coatings and Surface Modification Processes.........................................................4

Combined PVD and CVD Coating .........................................................................

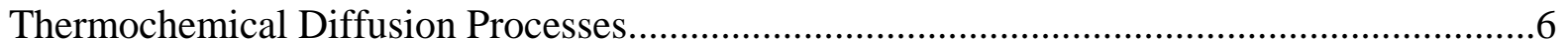

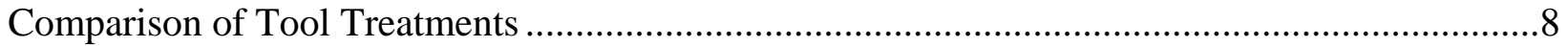

Selection of Candidate Processes ..............................................................................8

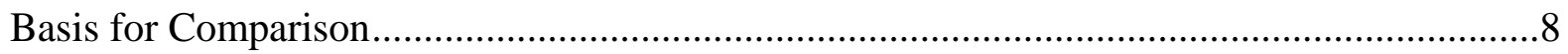

Coefficient of Friction ...........................................................................................

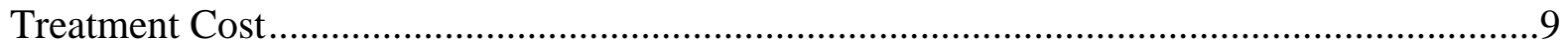

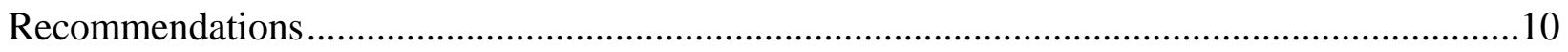

Development of Replacements for Phoscoating Used in Forging, Extrusion and Metal Forming

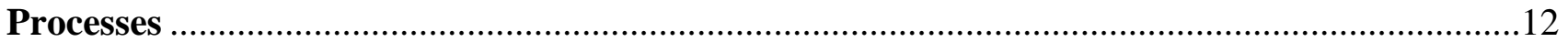

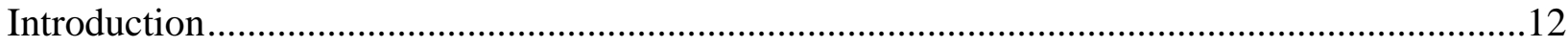

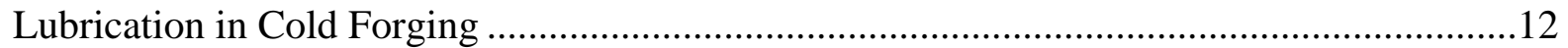

Problems Associated with the Use of Zinc Phosphate Coating Based

Lubricants in Cold Forging........................................................................................12

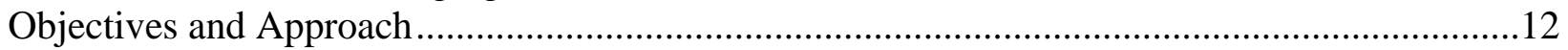

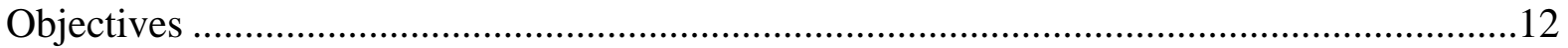

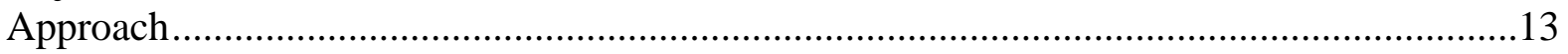

Survey of Lubricants for Replacement of Phoscoating .................................................... 14

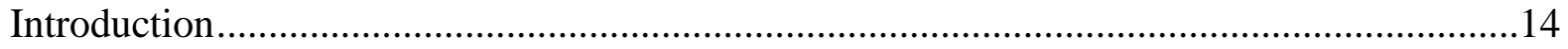

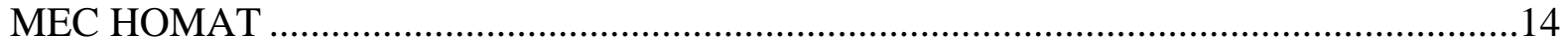

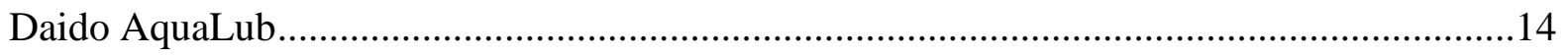

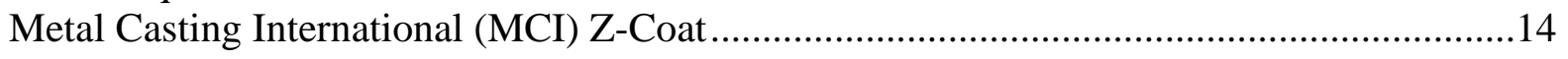

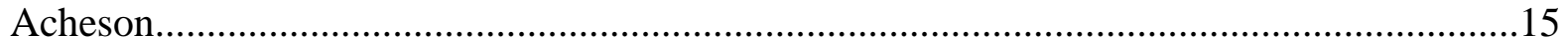

Finite Element Simulations of the Double Cup Backward Extrusion Test ................................15

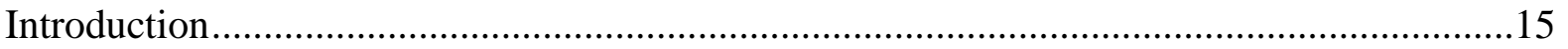

General Conditions for the FE Simulations .............................................................. 15

FE Simulation Results and Discussion .................................................................. 15

Evaluation of Candidate Lubricants by Double Cup Backward Extrusion Test Using

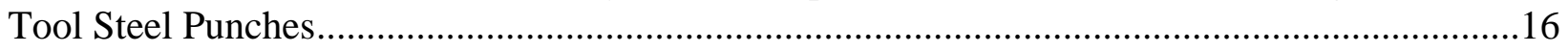

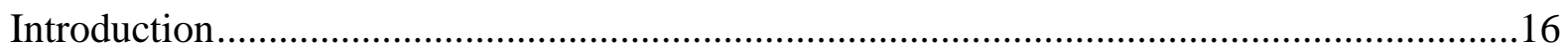

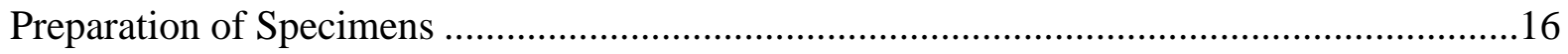


Application of Lubricants and Surface Characterization................................................18

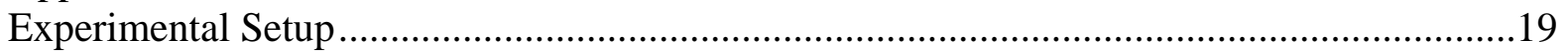

Determination of Appropriate Punch Stroke ............................................................... 19

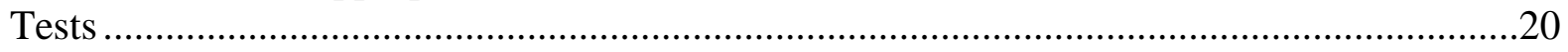

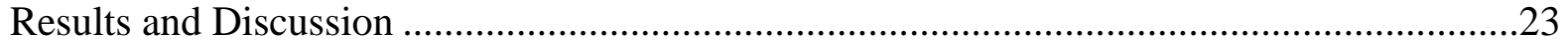

Evaluation of Candidate Lubricants by Double Cup Backward Extrusion Test

Using Carbide Punches .....................................................................................................24

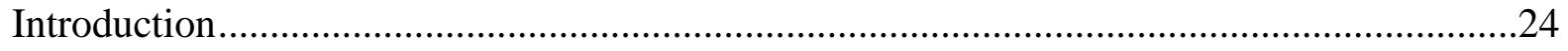

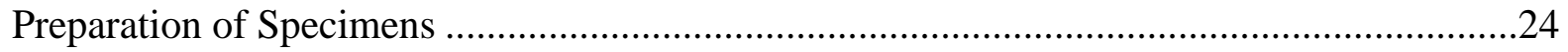

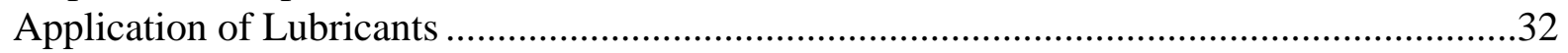

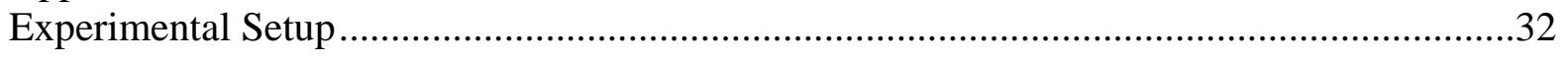

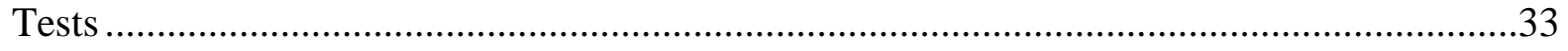

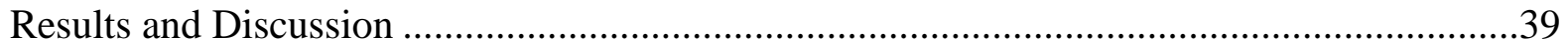

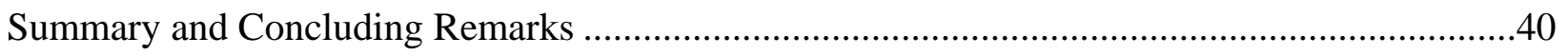

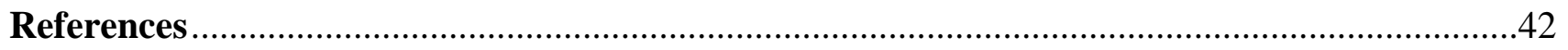




\section{List of Figures}

\section{Figure}

1. Forging Dies Undergoing Ion Nitriding (Advanced Heat Treat) ...............................................

2. Hardness Profile for Ion Nitrided D2 Tool Steel ..................................................................

3. Schematic of TD Process (Arvin TD Center) ………...........................................................

4. Wear and Friction Test Results for a MoST® PVD Coating on M42 Tool Steel ........................9

5. Coefficient of Friction for Ion Nitrided Alloy Steels and Stainless Steels ...................................

6. Coefficient of Friction for a D2 Tool Steel Surface Treated by the TD Process.........................10

7. Double Cup Backward Extrusion Test …………………….....................................................14

8. FE Model (Friction Factor $\mathrm{m}$ - 0.1) ………………............................................................16

9. Definition of the Cup Height Ratio and Real Stroke …….......................................................17

10. Friction Factor Calibration Curves (AISI 1038) ........................................................................17

11. Friction Factor Calibration Curves (AISI 8610) …………………............................................17

12. Double Cup Backward Extrusion Test Tooling ........................................................................18

13. Optical Micrographs of Lubricated Billet Surfaces Before Tests...............................................20

14. Double Cup Backward Extrusion Tooling: 3D Cross-Section View .........................................21

15. Surface Cracks in Billets Coated with MEC HOMAT at $27 \mathrm{~mm}$ Stroke ...................................21

16. Damage Value Distribution in Double Cup Extrusion for Low and High Friction.....................21

17a. Photographs of Selected Extruded Parts (AISI 8610) ……………………………...................22

17b. Photographs of Selected Extruded Parts (AISI 1038) ……………………………..................23

18. Lubricant Performance as a Function of Cup Height Ratio and Friction Factor

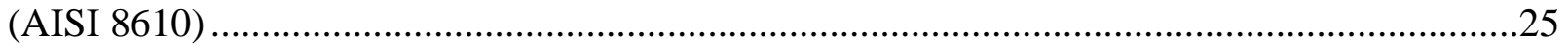

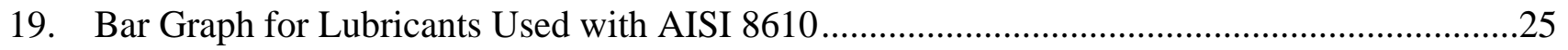

20. Lubricant Performance as a Function of Cup Height Ratio and Friction Factor

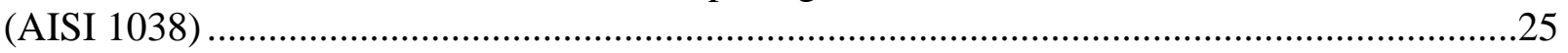

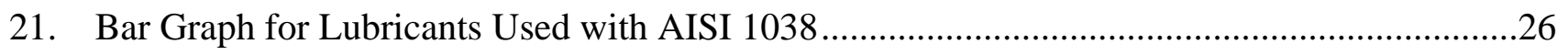

22. Performance Comparison Between Acheson and Phoscoating Lubricants .................................26 
23. Performance Comparison Between MEC HOMAT and Phoscoating Lubricants .26

24. Optical Micrographs After Tests in the Upper Cups (AISI 8610)......................................27

25. Optical Micrographs After Tests in the Lower Cups (AISI 8610) .......................................28

26. Optical Micrographs After Tests at the Outside Surface (AISI 8610) .................................29

27. Optical Micrographs After Tests in the Upper Cups (AISI 1038)........................................30

28. Optical Micrographs After Tests in the Lower Cups (AISI 1038) .......................................31

29. Optical Micrographs After Tests at the Outside Surface (AISI 1038) ..................................32

30. RP-48 Converted Radial Press with Extrusion Capability .................................................33

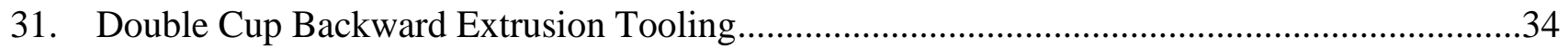

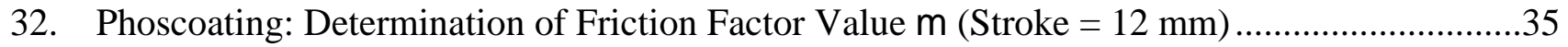

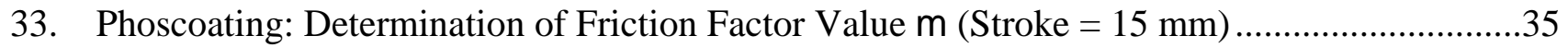

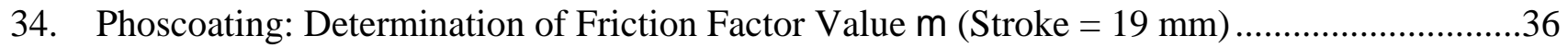

35. Acheson Lubricant: Determination of Friction Factor Value $\mathrm{m}($ Stroke $=12 \mathrm{~mm}) \ldots \ldots \ldots \ldots \ldots . . . . .36$

36. Acheson Lubricant: Determination of Friction Factor Value $\mathrm{m}($ Stroke $=15 \mathrm{~mm})$................36

37. Acheson Lubricant: Determination of Friction Factor Value $\mathrm{m}($ Stroke $=19 \mathrm{~mm}) \ldots \ldots \ldots \ldots \ldots . . . . .37$

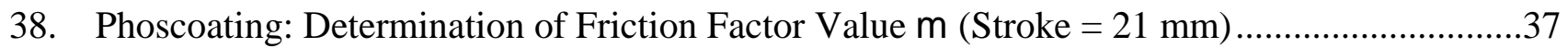

39. Acheson Lubricant: Determination of Friction Factor Value $m($ Stroke $=21 \mathrm{~mm}) \ldots \ldots \ldots \ldots \ldots . . . . .37$

40. Lubricant Performance as a Function of Cup Height Ratio and Friction Factor (12 mm Stroke and TiN Coated Punches) ......

41. Lubricant Performance as a Function of Cup Height Ratio and Friction Factor (15 mm Stroke and TiN Coated Punches) .....

42. Lubricant Performance as a Function of Cup Height Ratio and Friction Factor (19 mm Stroke and TiN Coated Punches) .....

43. Lubricant Performance as a Function of Cup Height Ratio and Friction Factor (21 mm Stroke and TiAlN + WCC Coated Punches)

44. Friction Factor for Various Stroke Lengths and Lubricants 39

45. Performance Comparison for Acheson and Phoscoating Lubricants (19 mm Stroke) 40 


\section{List of Tables}

Table

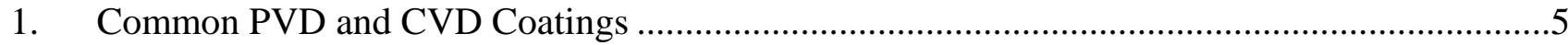

2. Comparison of Thermochemical Diffusion Processes.....................................................6

3. Friction Coefficient Measured During Cold Forming with Phoscoating Lubricant...................9

4. Cold Forging Case Histories and Cost Per Part for the Four Selected Tool Treatments............11

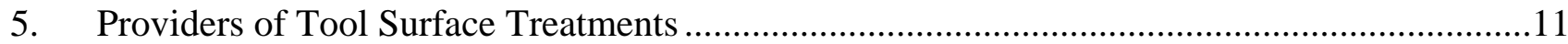

6. Material Properties Obtained from the Compression Test ...............................................15

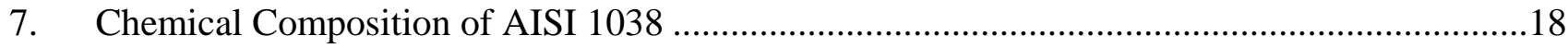

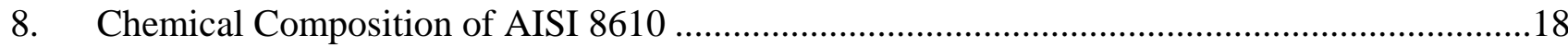

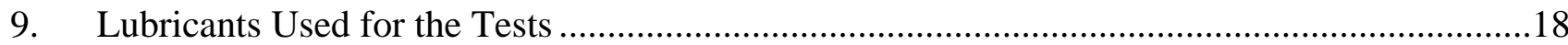

10. Experimental Matrix for the Double Cup Backward Extrusion Test ....................................21

11. Double Cup Backward Extrusion Tooling Materials .....................................................33

12. Experimental Matrix Used by Kinefac Corporation ...........................................................34 


\section{Acronyms and Abbreviations}

CETIM Centre Technique des Industries Mécaniques

PVD Physical vapor deposition

OIT Office of Industrial Technology

CVD Chemical vapor deposition

SwRI Southwest Research Institute

ERC/NSM Engineering Research Center for Net Shape Manufacturing

TD

Thermochemical diffusion

HV Vickers Hardness

$\mathrm{TiC}$

Titanium carbide

MCI Metal Coating International

U.S. $\quad$ United States

NCMS National Center for Manufacturing Sciences 


\section{Executive Summary}

\section{Background and Introduction}

Many forging, extrusion, heading and other metal forming processes use graphite-based lubricants, phosphate coatings, and other potentially hazardous or harmful substances to improve the tribology of the metal forming process. These lubricants provide relief in some or all of the following areas depending on the application and metal forming requirements:

- Overall friction reduction

- Improved heat transfer (both for process heating and for component cooling during forming

- Release agent at the die/workpiece interface

- Billet Protection where anti-oxidation may be possible

- Reduce metal forming friction loss between die and work

- Prevent die failure due to pickup of workpiece material on dies

- Improve die life due to reduced surface erosion

- Increase the level of metal flow achievable by forming

- Reduce process heat

- Provide anti-oxidation protection.

The application of phosphate-based coatings has long been studied to determine if other synthetic "clean" lubricants could provide the same degree of protection afforded by phoscoatings and its formulations. So far, none meets the cost and performance objectives provided by phoscoatings as a general aid to the metal forming industry. In as much as phoscoatings and graphite have replaced lead-based lubricants, the metal forming industry has had previous experience with a legislated requirement to change processes. However, without a proactive approach to phoscoating replacement, many metal forming processes could find themselves without a cost effective tribology material necessary for the metal forming process.

\section{The Problem}

Graphite coatings applied in the metal forming process tend to contribute to the housekeeping problems that plague metal forming operations, exist as air-borne particulate, and have generally limited the metal forming industry's confidence in microprocessor controls technology due to potential contamination concerns. Similarly, phosphate coatings require chemical processes that may be in danger of legislative phase-out and would require substantial investments in environmental controls technology to enable the metal forming industry to continue to process its parts. There exists a need to develop and adopt clean lubrication products and standards for the metal forming industry that would be compatible with complex metal forming requirements, enhance die and tooling life, be capable of high temperature product manufacturing, and would pre-empt environmental legislation that could impact graphite and phosphate coatings and their usage in the future. A focus on environmentally conscious manufacturing is consistent with the objectives of metal forming companies, metal forming equipment manufactures and the material and coating suppliers.

\section{Proposed Solution}

The National Center for Manufacturing Sciences (NCMS) held a workshop on September 28, 1999 in Dearborn, MI which provided the basis for a new project initiative of vital interest to the metal forming community. A holistic approach to replacement of phoscoatings was developed by the NCMS team and a description of the project and its tasks are provided by this report. 
The team, led by Delphi Saginaw, Kinefac Corporation, Metaldyne, Acheson Colloids, Ohio State University, Southwest Research Institute (SwRI), and NCMS organized itself around the replacement of phoscoatings to address legislation and environmental pressures in progress. Using tooling provided by the NCMS team, a number of alternative billet and tool coating materials would be assessed as independent and dependent variables for metal forming operations. Acheson Colloids, a supplier of lubricants and coatings to the metal forming industry, proposed that one of its most important emerging technologies be evaluated through this program. The Kinefac Corporation agreed to provide a hydraulic extrusion press to form billets supplied by Metaldyne Company using a double cup specimen test developed at Ohio State University. Delphi Saginaw would provide test tooling.

The following attributes were to be evaluated during this pilot program:

- Ease of application

- Durability of coating (survives harsh and changing environment)

- Coating adhesion

- Coating uniformity

- Reduction of co-efficient of friction

- Prediction of part forming temperatures

- Part tolerance upon forming.

The environmental issues to be addressed included the following:

- Generation of hazardous waste products

- Sludge

- Zinc based by products

- High water usage

- Human exposure to toxic chemicals and fumes

- High energy consumption
- Cleanability for post-processing (some operations require removal of phoscoating to accommodate downstream machining or finishing operations.

\section{Results and Recommendations}

\section{Survey of Coatings and Surface Modifica- tion Processes for Cold Forging Tooling}

Of the commercially available coatings and surface modification processes, the most suitable for cold forging under severe conditions were those with surface hardness above 1000 Vickers Hardness (HV) and a very low coefficient of friction (high lubricity). A thin-film coating could be used, but only if supported by an underlying coating or a surface modified underlayer. Surface modification could also be used on its own, and several thermochemical diffusion processes were suitable.

SwRI has selected four tool treatments. These were a MoST ${ }^{\circledR}$ physical vapor deposition (PVD) coating overlying a titanium carbide (TiC) chemical vapor deposition (CVD) coating, ion nitriding, boriding and the thermochemical diffusion (TD) process. The processes were compared on the basis of coefficient of friction and treatment cost per part. Friction data was obtained from laboratory test results. The cost per part was estimated from case histories for treated cold forging tools.

The friction data suggested that the combined PVD/CVD coating or the ion nitriding process have the potential to replace phoscoating in cold forging. This was because the coefficient of friction for these treatments was comparable to that measured for phoscoating. However, a quantitative comparison between the four selected treatments was difficult due to unknown contact pressures in some of the friction tests.

The cost per part for three of the four tool treatments appeared to be comparable to or 
lower than the cost of phoscoating. But the only accurate cost estimate was for the combined PVD/CVD coating, with which the need for phoscoating was completely eliminated.

SwRI recommends evaluation of all four tool treatments as possible replacements for phoscoating in cold forging operations.

\section{Development of Replacements for Phos- coating Used in Forging, Extrusion and Metal Forming Process}

In order to replace zinc phosphate partially or completely, candidate lubricants were sought from lubricant manufacturers worldwide. Four lubricant candidates were identified, namely: MEC HOMAT, Daido AquaLub, MCI Z-Coat and Acheson.

The performance evaluation of these lubricants was conducted using the double cup backward extrusion test developed at Ohio State University's Engineering Research Center for Net Shape Manufacturing (ERC/NSM). The principle underlying this test was that the cup height ratio was an indication of lubricity. In this test, however, friction factor was determined indirectly by combining FEM and experiments. Thus, calibration curves, i.e. cup height ratio vs. punch stroke, were established with FEM by varying friction factor $(m)$ from $m=0$ to $m=0.15$. In order to conduct the FE simulations, the flow stress of the materials used in the experiments had to be determined. Two billet materials, AISI 8610 and AISI 1038, were used in this study.
The punches and die container used for the double cup backward extrusion tooling were made from tool steel (M2).

Four lubricants, MEC HOMAT, Daido AquaLub, MIC Z-Coat, and phoscoating, were tested on the AISI 8610 billets. In this set of tests, MEC HOMAT was found to have the best performance. For the AISI 1038 billets, only the Acheson lubricant and phoscoating were tested. In these tests, phoscoating performed better than the Acheson lubricant. In addition, a ranking showing the performance of the candidate lubricants in comparison to the conventional phoscoating was achieved. In the future, subsequent testing of the viable candidate lubricants should be completed in a production environment.

In order to further evaluate the Acheson lubricant as compared to phoscoating, a series of double cup backward extrusion tests were conducted at the Kinefac Corporation. The billets were cut from the same AISI 1038 stock as the billets used by the ERC/NSM. The geometry of the forming tooling was identical to that developed at the ERC/NSM; however, the punches were made from carbide as opposed to M2 tool steel. In addition, the Kinefac Corporation was able to incorporate two punch coatings, namely TiN and TiAlN + WCC, into their tests.

Just as in the tests performed at the ERC/NSM, the phoscoating performed better than the Acheson lubricant. In addition, the results showed little difference between the TiN and the TiAlN + WCC punch coatings. 


\section{Survey of Coatings and Surface Modification Processes for Cold Forging Tooling}

\section{Introduction}

The Ohio State University's Engineering Research Center for Net Shape Manufacturing (ERC/NSM) is investigating the replacement of phoscoating used for lubrication in forging, extrusion and metal forming processes. The objective of the project is to replace phoscoating without losing the favorable properties of the lubricant. The particular emphasis of the study is cold forging under extreme conditions, a process in which good lubrication is essential. Without a lubricant, the billet being forged is likely to crack.

Phoscoating consists of zinc phosphate coating followed by application of a reactive soap, a combination discovered by German engineers making steel shell casings in the 1930s. The soap reacts with the phosphate to form what is believed to be a chemically bonded lubricant layer. Zinc phosphate has the ability to absorb and hold lubricants such as the stearates in soap, even under severe conditions of heat and pressure. Because phoscoating is so effective, its use has continued to the present.

However, phosphate sludge and wastewater from the phoscoating process are environmentally hazardous, and their proper disposal is becoming increasingly costly. In addition, phosphating and dephosphating of parts adds to the cost of cold forming. The cold forging industry in particular is pushing for an alternative to phoscoating.

A formal survey of candidate lubricants has been completed by ERC/NSM. Southwest Research Institute's (SwRI) role in the project is to search for additional possibilities. These include other lubricants, as well as surface treatments for the tooling used in cold forging operations. The ultimate goal is to eliminate the need for a lubricant altogether. Similar efforts on surface treatments for tooling are under way elsewhere, for example at the Darmstadt University of Technology in Germany.

Since ERC/NSM already has a substantial list of possible replacement lubricants, SwRI has limited its search to coatings and surface modification processes for cold forging tooling. Tools for cold forging are usually made from a tool steel, sometimes with carbide inserts.

\section{Candidate Coatings and Surface Modification Processes}

Cold forging under extreme conditions involves very high forces on the tooling, with contact pressures typically in the range $0.8-1.5 \mathrm{GPa}$ (120$220 \mathrm{ksi}$ or $50-100$ tons per in ${ }^{2}$ ). A lubricant like phoscoating is needed for all types of cold forming at such high pressures, and any replacement lubricant or tool surface treatment must also be able to withstand these harsh conditions. At lower contact pressures, other lubricants that are more environmentally benign can be substituted.

Surface treatments for tooling can be divided into coatings and surface modification processes. Coating processes deposit an overlayer on the surface while surface modification alters the properties of the near-surface region without a new layer being added.

Most thin-film coatings will not stand up to cold forging pressures when used alone. Such coatings are generally thinner than the case depth of a surface modification process. Under cold forging conditions, thin-film coatings deposited by physical vapor deposition (PVD) or chemical vapor deposition (CVD) are likely to crack or even delaminate. This immediately excludes the vast majority of commercially available PVD or CVD coatings as a treatment for forging tools. 
However, a PVD or CVD coating can be used for cold forging tools when deposited over another coating, or on top of a surface modified underlayer. In this instance, the underlying coating or surface modification process provides support for the overlay coating. The top coating is not subject to the "eggshell effect" experienced by a thin, unsupported coating on a softer substrate.

The best coating combination is probably a lubricious PVD film deposited over a CVD coating. Not only are CVD coatings thicker than PVD coatings, but they are also more robust.

This is because the high deposition temperature causes coating atoms to diffuse into the substrate, so that the films are strongly adherent. CVD coatings, however, do not have high lubricity.

An alternative treatment for cold forging tooling is a surface modification process. Surface modification can be used either on its own or as support for an overlying PVD coating. The deep, hardened case that results from most surface modification processes will hold up even under the extreme pressures of cold forging.

\section{Combined PVD and CVD Coating}

PVD is a thin-film deposition process based on emission of vapor from a source, its transport in a vacuum and its condensation on a heated substrate. For deposition of chemical compounds, a reactive gas is introduced into the vapor stream. Substrate temperatures range from about $200^{\circ} \mathrm{C}\left(390^{\circ} \mathrm{F}\right)$ to $550^{\circ} \mathrm{C}\left(1020^{\circ} \mathrm{F}\right)$, depending on the PVD method. The most common methods are cathodic arc evaporation, electron beam evaporation and sputtering. PVD is sometimes referred to as "the cold process."

CVD, often called "the hot process," involves a chemical reaction between gases on the surface of a heated substrate. The reaction product condenses on the substrate. CVD temperatures are usually $800-200^{\circ} \mathrm{C}\left(1470-2190^{\circ} \mathrm{F}\right)$, high enough to cause distortion and loss of bulk hardness in many materials. However, the high temperatures lead to metallurgical bonding of the coatings.

Many PVD and CVD coatings are single-layer. However, multi-layer coatings, that combine the properties of the component layers, are becoming increasingly popular. Multi-layer CVD coatings have been used for some time on cutting tool inserts, and several multi-layer PVD coatings have recently emerged also. An interlayer is sometimes deposited between a PVD coating and the substrate, to enhance adhesion.

Some common PVD and CVD coatings are listed in Table 1.

The most important needs in a coating on tooling are high hardness and a low coefficient of friction. Tool wear decreases with increasing hardness and decreasing coefficient of friction. Friction data for the candidate coatings and surface modification processes will be reviewed later in this report. For long tool life, the surface hardness should be $1000 \mathrm{HV}$ or higher, a condition satisfied by essentially all PVD and CVD coatings.

Table 1. Common PVD and CVD Coatings

\begin{tabular}{|l|c|c|c|c|}
\hline Coating & $\begin{array}{l}\text { PVD or } \\
\text { CVD }\end{array}$ & $\begin{array}{c}\text { Typical Coating } \\
\text { Thickness, } \mu \mathrm{m}\end{array}$ & Hardness, HV & Adhesion $^{1}$ \\
\hline TiN & PVD & $1-5$ & $2,300-2,900$ & 70 \\
\hline TiCN & PVD & $1-5$ & $3,000-3,500$ & 62 \\
\hline Diamond-like carbon (DLC) & PVD & $1-10$ & $1,000-5,000$ & Unknown \\
\hline MoST ${ }^{2}$ & PVD & $2-5$ & $1,500-2,100$ & $>120$ \\
\hline TiC & CVD & $7-10$ & $3,000-3,200$ & Unknown \\
\hline TiC/TiN & CVD & $7-10$ & $2,600-2,800$ & 110 \\
\hline
\end{tabular}

1 Critical normal force (newtons) required to remove coating from substrate in scratch test

$2 \mathrm{MoS}_{2} / \mathrm{Ti}$ composite coating developed by Teer Coatings and licensed to IonBond 


\section{Thermochemical Diffusion Processes}

Surface modification processes include thermochemical diffusion and ion implantation. Implantation is unsuitable for applications involving heavy loading like cold forging, because of the shallow depth of the process. The principal thermochemical diffusion processes are summarized in Table 2 .

Thermochemical diffusion (TD) involves adsorption of an element such as carbon or boron on a heated metal substrate. This is followed by a chemical reaction between the element and substrate, and diffusion of the element into the metal. Several methods of diffusion can be used. The methods are: salt bath (from the liquid state), gas, vacuum, ion (plasma), fluidized bed and pack cementation (solid). Process temperatures for diffusion can be as high as $1050^{\circ} \mathrm{C}\left(1920^{\circ} \mathrm{F}\right)$, which may result in distortion of a tool and loss of core hardness.

Of the various diffusion treatments, carburizing results in the deepest case layers, but is restricted to carbon and alloy steels. Case depths for nitriding and carbonitriding processes range up to $750 \mu \mathrm{m}$ for carbon and alloy steels, and up to $250 \mu \mathrm{m}$ for stainless and tool steels. Nitrocarburizing and boriding generally produce shallower case layers less than $100 \mu \mathrm{m}$ deep, but can penetrate $500 \mu \mathrm{m}$ or more when required. The TD process produces a case no more than $20 \mu \mathrm{m}$ deep. However, even this depth should be adequate for cold forging dies.

As with thin-film coatings, the surface hardness for long tool life should be $1000 \mathrm{HV}$ or higher. This requirement restricts the choice of possible diffusion treatments (Table 2) to nitriding, boriding and the TD process. Each of these is now discussed in turn.

\section{lon Nitriding}

Within nitriding, SwRI has selected the ion nitriding (plasma nitriding) method, since this has the lowest process temperature and shortest process time of all the available diffusion methods. In ion nitriding, nitrogen is diffused into the substrate from a glow discharge plasma (Figure 1). The substrate is negatively biased to about $-1 \mathrm{kV}$ and the bias voltage is usually pulsed to minimize arcing.

An ion nitrided steel surface comprises an outer compound zone and an underlying diffusion zone. The compound zone, often called the white layer, consists of iron compounds and is up to $15 \mu \mathrm{m}$ thick. The much deeper diffusion zone consists of nitrogen in solid solution, together with finely dispersed nitride precipitates.

Table 2. Comparison of Thermochemical Diffusion Processes

\begin{tabular}{|l|c|c|c|}
\hline Process & $\begin{array}{c}\text { Typical Case Depth, } \boldsymbol{\mu m} \\
\text { (mils) }\end{array}$ & $\begin{array}{c}\text { Surface Hardness, } \\
\text { HV }\end{array}$ & $\begin{array}{c}\text { Typical Process } \\
\text { Temperature, }{ }^{\circ} \mathbf{C}\left({ }^{\circ} \mathrm{F}\right)\end{array}$ \\
\hline Carburizing & $\begin{array}{c}75-1,500 \\
(3-60)\end{array}$ & $700-900$ & $\begin{array}{c}850-950 \\
(1,560-1,740)\end{array}$ \\
\hline Nitriding & $\begin{array}{c}75-750 \\
(3-30)\end{array}$ & $300-1,050$ & $\begin{array}{c}500-570 \\
(930-1,060)\end{array}$ \\
\hline Carbonitriding & $\begin{array}{c}50-750 \\
(2-30)\end{array}$ & $600-850$ & $\begin{array}{c}750-900 \\
(1,380-1,650)\end{array}$ \\
\hline Nitrocarburizing & $\begin{array}{c}25-750 \\
(1-30)\end{array}$ & $500-6501$ & $\begin{array}{c}560-670 \\
(1,040-1,240)\end{array}$ \\
\hline Boriding (boronizing) & $\begin{array}{c}25-125 \\
(1-5)\end{array}$ & $1,600-2,000$ & $\begin{array}{c}820-980 \\
(1,510-1,800)\end{array}$ \\
\hline TD Process & $\begin{array}{c}2.5-20 \\
(0.1-0.8)\end{array}$ & $3,200-3,800$ & $\begin{array}{c}850-1,050 \\
(1,560-1,920)\end{array}$ \\
\hline
\end{tabular}

1 Mild steel 


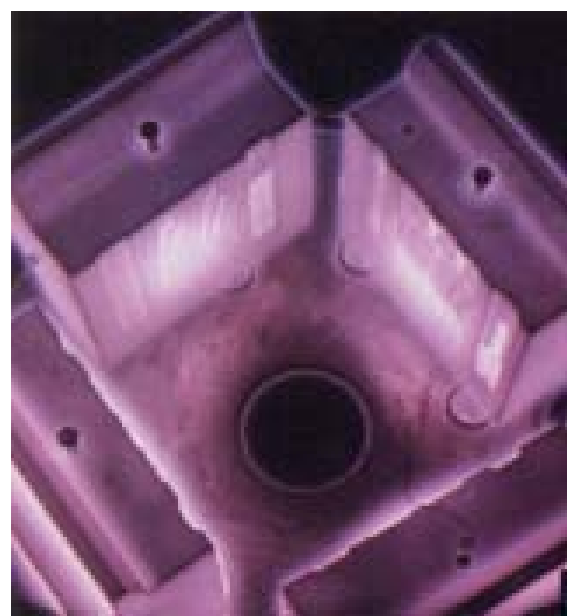

Figure 1. Forging Dies Undergoing lon Nitriding (Advanced Heat Treat)

One of the characteristics of thermochemical diffusion is that the increased hardness from the process is graduated. The hardness has its highest value at the surface and gradually falls to the bulk value over the case depth. An example is shown in Figure 2.

\section{Boriding}

Boriding (boronizing) is done by the pack cementation method. In this method, parts are immersed in a powder material containing a source of boron. The powder pack is placed in a sealed container that is then transferred to a furnace. Boron diffuses into the parts and forms borides of the base metal.

Two boride phases can form on steels. The FeB phase is brittle and results in a surface under high tensile stress. The $\mathrm{Fe}_{2} \mathrm{~B}$ phase is preferred because it is less brittle and results in a surface

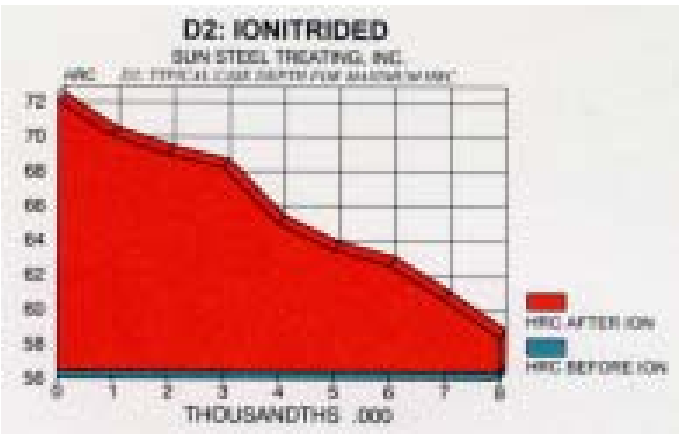

Figure 2. Hardness Profile for Ion Nitrided D2 Tool Steel with high compressive stress. Formation of continuous layers of $\mathrm{FeB}$, that could lead to spalling, can be minimized by diffusion annealing after boriding. Also, boriding powders that reduce formation of $\mathrm{FeB}$ are available.

As in ion nitriding, the hardness following boriding is highest at the surface. Although the core hardness of a tool steel is generally lowered by the high temperature $\left(820-980^{\circ} \mathrm{C}\right)$ of boron diffusion, most tool steels can be rehardened without affecting the borided surface layer.

\section{TD Process}

The TD process, originally developed by Toyota, uses the salt-bath diffusion method to create a carbide layer at the surface. The carbide is formed from the diffused element and carbon already present in the substrate. Most commonly, vanadium is diffused to form a vanadium carbide layer (Figure 3). The substrate must contain a minimum of $0.3 \%$ carbon for the necessary chemical reaction to occur.

Vanadium carbide is very hard, with hardness ranging from 3,200 to 3,800 on the Vickers scale. This hardness is retained at temperatures up to $550^{\circ} \mathrm{C}\left(1,020^{\circ} \mathrm{F}\right)$. The case layer produced by the TD process exhibits uniform hardness, in contrast to the graduated hardness produced by other thermochemical diffusion processes. However, despite the abrupt transition from the vanadium carbide layer to the undiffused metal underneath, the layer shows extremely strong bonding to the substrate.

Because the TD process temperature is so high $\left(850-1,050^{\circ} \mathrm{C}\right)$, steels are processed at their recommended austenizing temperature. After TD processing, parts are quenched, and then tempered to restore the original core hardness. 


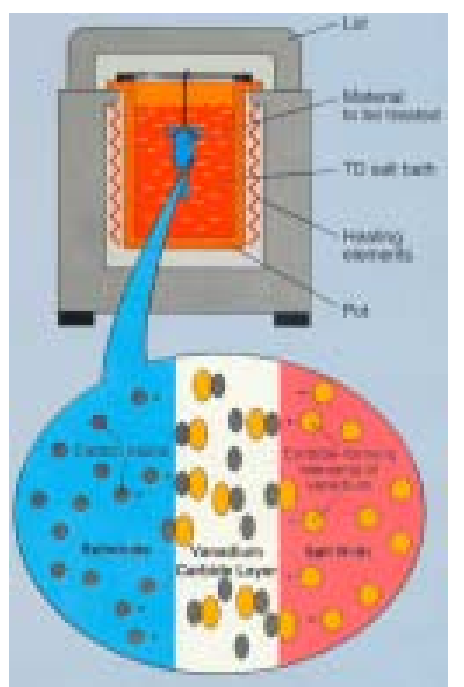

Figure 3. Schematic of TD Process (Arvin TD Center)

\section{Comparison of Tool Treatments}

\section{Selection of Candidate Processes}

There are many possible combinations of a PVD coating with another coating or a surface modified underlayer. In this search, SwRI has selected a PVD deposited over a CVD coating, together with three thermochemical diffusion processes on their own.

The selected coating combination is an MoST® PVD coating overlying a TiC CVD coating (highlighted in Table 1). This has been chosen for two reasons:

- MoST® is a PVD solid (dry film) lubricant that exhibits an ultralow coefficient of friction, often lower than that of Teflon ${ }^{\circledR}$ or graphite. But unlike other solid lubricants, MoST $®$ has a hardness approaching that of TiN. The only other commercial PVD coating with comparable lubricity and hardness is DLC.

- The combination of MoST® PVD with TiC CVD has already been used successfully on a cold forging tool. An M2 tool steel punch used in backward extrusion was treated by IonBond. The treatment not only prolonged tool life, but it also eliminated the need for phoscoating - the objective of the present project. In less arduous applications, MoST® PVD has proved superior to TiC/TiN CVD coatings.

The three selected diffusion processes discussed are: ion nitriding, boriding and the TD process (highlighted in Table 2).

\section{Basis for Comparison}

The four selected tool treatments are now compared for their potential to reduce or eliminate the use of phoscoating in cold forging.

Our first basis for comparison of the treatments is coefficient of friction. The purpose of a lubricant is to prevent the two surfaces in sliding motion from coming into direct contact, a condition that leads to severe adhesive wear (galling). A lubricant film, either liquid or solid, keeps the surfaces separated and lowers frictional forces. The coefficient of friction between the surfaces is a measure of the lubricity.

A second basis for comparison is the treatment cost per part produced, relative to phoscoating. This is an important attribute, since the cold forging industry is already concerned about the high overall cost of the phoscoating process.

\section{Coefficient of Friction}

\section{Phoscoating Lubricant}

The coefficient of friction during cold forming with a phoscoating lubricant has been measured by the Centre Technique des Industries Mécaniques (CETIM) in France. The measurements were part of an investigation of a new cold forging lubricant developed by Dacral. Information on this lubricant, gathered in the earlier survey, was provided to SwRI by ERC/NSM.

CETIM determined the coefficient of friction both for wire drawing and forward extrusion operations, under actual production conditions. Although wire drawing is not a cold forging process, contact pressures on wire drawing dies 
are often in the cold forging range (0.8-1.5 $\mathrm{GPa})$. Values of the friction coefficient $\mu$ were measured using phoscoating as well as the new Dacral lubricant. The phoscoating results are shown in Table 3.

It is seen that $\mu$ ranges from 0.062 to 0.10 , and increases as the contact pressure increases.

\section{Candidate Tool Treatments}

Friction data for the candidate tool treatments have been obtained from laboratory test results. For direct comparison to the phoscoating data, results for unlubricated motion (dry sliding) are necessary. The presence of a lubricant modifies the frictional behavior of the coating or diffusion treatment.

Typical data from unlubricated pin-on-disk testing of an MoST® PVD coating, without an underlying TiC coating, are presented in Figure 4. Only the tool steel disk was coated, not the WC-6\% Co pin.

Results from unlubricated pin-on-disk tests of an ion nitrided surface are shown in Figure 5. For these tests, both the steel disks and the 440C stainless steel pin were nitrided.

Figure 6 shows results from a lubricated sliding test of a TD-treated tool steel surface. Wear was produced by a diamond tip under load, and the lubricant was $\mathrm{MoS}_{2}$. No graphical data are available for an unlubricated TD-treated surface, nor for a borided surface.

Because of the unknown contact pressures, a quantitative comparison between the processes is not straightforward. As expected, the values of $\mu$ for lubricated sliding are lower than those for unlubricated sliding.

Table 3. Friction Coefficient Measured During Cold Forming with Phoscoating Lubricant

\begin{tabular}{|l|c|c|}
\hline \multicolumn{1}{|c|}{ Cold Forming Process } & $\begin{array}{c}\text { Contact } \\
\text { Pressure, GPa }\end{array}$ & $\begin{array}{c}\text { Friction } \\
\text { Coefficient }\end{array}$ \\
\hline Wire drawing & 0.8 & 0.062 \\
\hline Forward extrusion & 1.38 & 0.10 \\
\hline
\end{tabular}

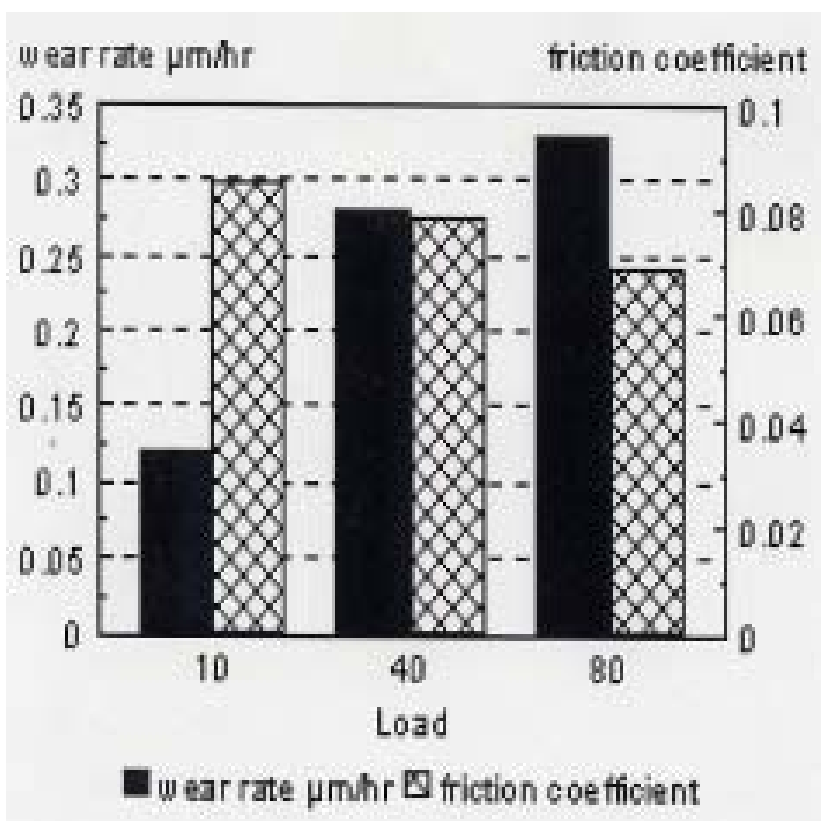

Figure 4. Wear and Friction Test Results for a MoST ${ }^{\circledR}$ PVD Coating on M42 Tool Steel

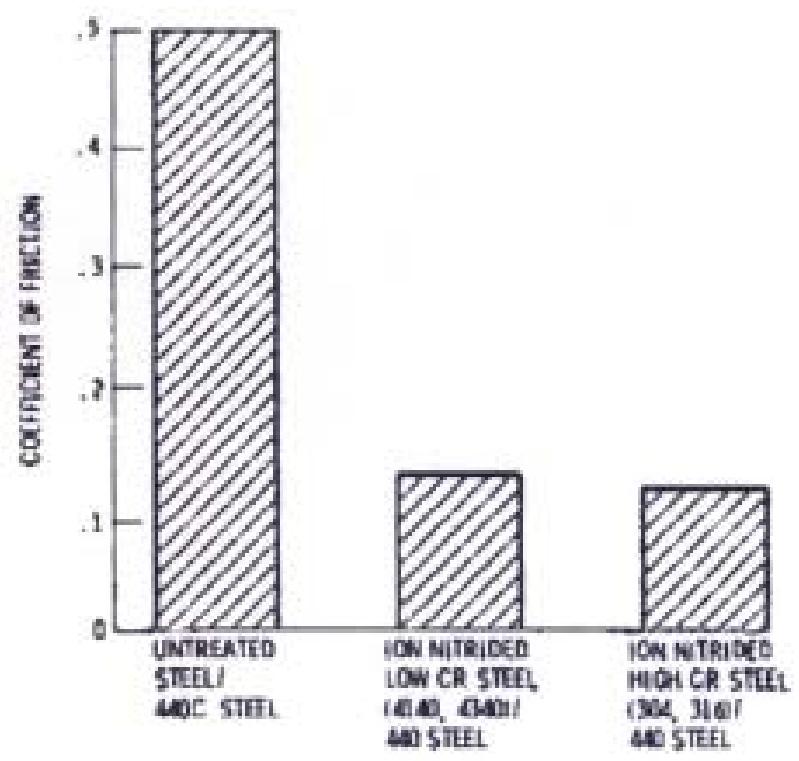

Figure 5. Coefficient of Friction for Ion Nitrided Alloy Steels and Stainless Steels

\section{Treatment Cost}

The cost of phoscoating in cold forging operations has been examined by MEC International. Like Dacral, this company developed a new cold forging lubricant, information on which was provided to SwRI by ERC/NSM. At least in 


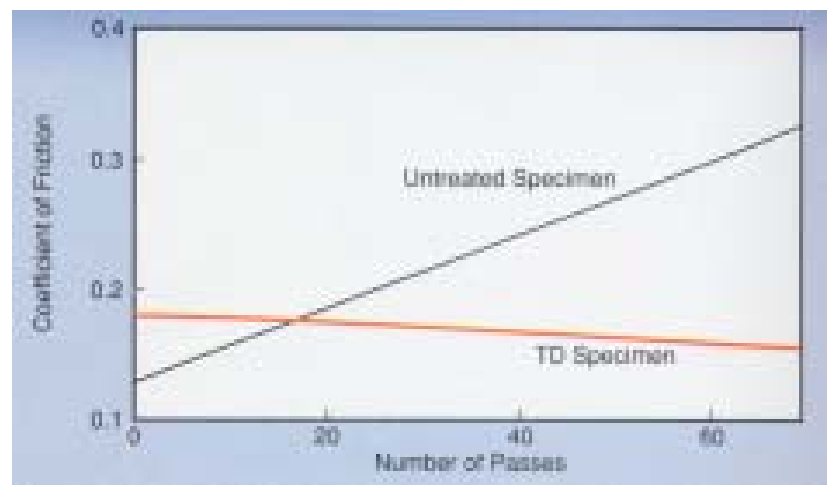

Figure 6. Coefficient of Friction for a D2 Tool Steel Surface Treated by the TD Process

Japan, MEC International estimates that phoscoating costs approximately $\$ 0.09$ (11.7 yen) per part in cold forging. Much of this cost is associated with the steps involved in phosphating, and with waste disposal.

To estimate the cost per part for the four selected tool treatments, SwRI has obtained information on treated tooling from providers of the treatments. For three of the four treatments, detailed case histories for cold forging tooling were available. For boriding, no cold forging history was available, and only a general cost comparison can be made between boriding and ion nitriding.

Table 4 compares the costs for the four selected treatments with the cost of phoscoating.

For all selected treatments except boriding, the calculated cost per part is lower than the estimated cost of $\$ 0.09$ for phoscoating. The costs of $<\$ 0.05$ per part for the MoST® PVD over
TiC CVD coating, and $\$ 0.036$ per part for the TD process, are promising. However, only with the combined PVD/CVD coating was the need for phoscoating eliminated altogether. For both ion nitriding and the TD process, the true cost per part is higher than the calculated cost in Table 4 because phoscoating was still necessary, though at a reduced level.

\section{Recommendations}

The friction and cost data suggest that three of the selected tool treatments have the potential to replace, or at least reduce the use of, phoscoating in cold forging. These are the MoST® PVD over TiC CVD coating, ion nitriding and the TD process. Boriding appears to have a higher coefficient of friction and to be more expensive. However, a detailed comparison between the four treatments is difficult due to unknown contact pressures in some of the friction tests, and lack of reliable cost information for boriding.

Therefore, SwRI recommends evaluation of all four tool treatments as possible replacements for phoscoating in cold forging operations.

Providers of the treatments are listed in the Table 5. In the case of the combined PVD/CVD coating, and also the TD process, there is only one U.S. provider for each process. In the case of ion nitriding and boriding, the two largest and most well-known providers are listed for each process. 
Table 4. Cold Forging Case Histories and Cost Per Part for the Four Selected Tool Treatments

\begin{tabular}{|c|c|c|c|c|c|c|}
\hline $\begin{array}{c}\text { Tool } \\
\text { Treatment }\end{array}$ & Tool & Application & $\begin{array}{c}\text { Treatment } \\
\text { Cost }\end{array}$ & $\begin{array}{c}\text { Number of } \\
\text { Parts }\end{array}$ & $\begin{array}{c}\text { Cost per } \\
\text { Part }\end{array}$ & Comments \\
\hline $\begin{array}{c}\text { MoST® PVD + } \\
\text { TiC CVD }\end{array}$ & $\begin{array}{c}\text { Extrusion } \\
\text { punch (M2) }\end{array}$ & $\begin{array}{c}\text { Backward extrusion of } 1035 \text { steel, } \\
\text { 400 ton press }\end{array}$ & $\$ 1,500$ & $>30,000$ & $<\$ 0.05$ & $\begin{array}{c}\text { Replaced } \\
\text { phoscoating } \\
\text { lubricant }\end{array}$ \\
\hline Ion nitriding & $\begin{array}{c}\text { Cold forging } \\
\text { die (D2) }\end{array}$ & Unknown & $\$ 600$ & 8,000 & $\$ 0.075$ & $\begin{array}{c}\text { Use of } \\
\text { phoscoating } \\
\text { reduced }\end{array}$ \\
\hline Boriding & $\begin{array}{c}\text { No history } \\
\text { available }\end{array}$ & $\begin{array}{c}\text { Approx. } 5 x \\
\text { cost of ion } \\
\text { nitriding }\end{array}$ & $\begin{array}{c}\text { Typically same } \\
\text { as ion nitriding }\end{array}$ & & \\
\hline TD process & $\begin{array}{c}\text { Extrusion } \\
\text { punch (M2) }\end{array}$ & $\begin{array}{c}\text { Backward extrusion of } 1010 \text { steel, } \\
\text { pressure } 1.5-1.7 \mathrm{GPa}\end{array}$ & $\$ 1,720$ & 48,000 & $\$ 0.036$ & $\begin{array}{c}\text { Use of } \\
\text { phoscoating } \\
\text { reduced }\end{array}$ \\
\hline $\begin{array}{c}\text { No treatment } \\
\text { (phoscoating } \\
\text { only) }\end{array}$ & $\begin{array}{c}\text { Extrusion } \\
\text { punch (M1) }\end{array}$ & $\begin{array}{c}\text { Backward extrusion of } 1010 \text { steel, } \\
\text { pressure } 1.5 \mathrm{GPa}\end{array}$ & Unknown & Unknown & $\$ 0.09$ & $\begin{array}{c}\text { Cost in } \\
\text { Japan }\end{array}$ \\
\hline
\end{tabular}

Table 5. Providers of Tool Surface Treatments

\begin{tabular}{|c|c|c|c|c|}
\hline Treatment & Company & Address & Contact, Title & Phone \\
\hline $\begin{array}{l}\text { PVD/CVD } \\
\text { coating }\end{array}$ & $\begin{array}{l}\text { IonBond } \\
\text { www.ionbond.com } \\
\end{array}$ & $\begin{array}{l}1598 \mathrm{E} \text {. Lincoln } \\
\text { Madison Heights, Ml } \\
48071\end{array}$ & $\begin{array}{l}\text { Bernie Janoss } \\
\text { Business Director, Stamping } \\
\text { \& Forming }\end{array}$ & $248-398-9100$ \\
\hline \multirow[t]{2}{*}{ Ion nitriding } & $\begin{array}{l}\text { Advanced Heat Treat } \\
\text { www.ahtweb.com }\end{array}$ & $\begin{array}{l}1625 \text { Rose Street } \\
\text { Monroe, Ml } 48162\end{array}$ & $\begin{array}{l}\text { Dr. Ed Rolinski } \\
\text { VP of Technology }\end{array}$ & 734-243-0063 \\
\hline & $\begin{array}{l}\text { Sun Steel Treating } \\
\text { www.sunsteeltreating.com }\end{array}$ & $\begin{array}{l}550 \text { Mill Street, Box U } \\
\text { South Lyon, MI } 48178\end{array}$ & $\begin{array}{l}\text { George Idriceanu } \\
\text { Director of R\&D and Process } \\
\text { Engineering }\end{array}$ & 248-471-0844 \\
\hline \multirow[t]{2}{*}{ Boriding } & $\begin{array}{l}\text { Bodycote Thermal Processing } \\
\text { www.bodycote.com }\end{array}$ & $\begin{array}{l}620 \text { Buffalo Road } \\
\text { Rochester, NY } 14611\end{array}$ & Keith Stewart & $585-436-7876$ \\
\hline & $\begin{array}{l}\text { Materials Development Corporation } \\
\text { www.vbcgroup.com/vbc/borofuse.htm }\end{array}$ & $\begin{array}{l}81 \text { Hicks Avenue } \\
\text { Medford, MA } 02155\end{array}$ & & $781-391-0400$ \\
\hline TD process & $\begin{array}{l}\text { Arvin TD Center } \\
\text { www.arvintd.com } \\
\end{array}$ & $\begin{array}{l}2020 \text { Fifteenth Street } \\
\text { Columbus, IN } 47201\end{array}$ & $\begin{array}{l}\text { Steve Harper } \\
\text { Manager of Engineering and } \\
\text { R\&D }\end{array}$ & 812-378-1592 \\
\hline
\end{tabular}




\section{Development of Replacements for Phoscoating Used in Forging, Extrusion and Metal Forming Processes}

\section{Introduction}

\section{Lubrication in Cold Forging}

In cold forging operations, pressures as high as 2,500 MPa (363 ksi) are developed at the toolworkpiece interface. In addition, the spike temperature may reach as high as $600^{\circ} \mathrm{C}$, and the surface enlargement may reach $3,000 \%$ [Bay, 1994].

Thus, the lubricants used in cold forging are subjected to very severe conditions. Failure to withstand the above-mentioned conditions implies failure to satisfactorily form the desired part and may lead to significant die wear or even die failure. A good lubrication system is essential for cold forging processes and it is the determining factor for making the process competitive.

Since 1934, nearly all steel cold forging processes have used a zinc phosphate coating based lubricant in order to withstand the severe conditions described above. The use of this lubricant, however, has a negative environmental impact. Thus, an environmentally friendly lubricant capable of replacing zinc phosphate based coatings is needed.

\section{Problems Associated with the Use of Zinc Phosphate Coating Based Lubricants in Cold Forging}

Before addressing candidate lubricants for the replacement of zinc phosphate coating based lubricants in cold forging, the problems associated with this lubrication system must be clearly stated. These problems include [Schmoeckel et al. 1997]:

- It is costly to apply and remove the zinc phosphate layer.
- Several baths at temperatures between 40 and $95^{\circ} \mathrm{C}$ containing different solutions are necessary. This results in high costs to purchase and maintain the equipment and high energy consumption to heat the baths.

- The amount of hazardous waste that is generated is a concern. The baths contain acids, ions of the basic metal, the alloying constituents, and phosphates. The wastewater contains organic compounds and emulsifying agents. After phosphating, the baths become polluted with heavy metals like lead and cadmium. The wastewater treatment and the baths result in solids, which contain metals, heavy metals, oils, and other pollutants. Most of this waste cannot be reused and thus becomes hazardous waste.

- The machines and facilities become polluted. Dust accumulates as the result of surface enlargement during forging. This dust is a health risk to the workers in the facility. The baths are also a source of toxic chemicals and fumes, which lead to unhealthy working conditions.

- The mechanical properties of the base material that the zinc phosphate coating is applied to are affected. Zinc phosphate can increase corrosion and diffuse into the workpiece material during heat treatment. This is a common cause for surface embrittlement.

\section{Objectives and Approach}

\section{Objectives}

The objective of this project was to replace phoscoating with other lubricants without losing the favorable properties that are obtained in metal forming operations using phoscoating. To select candidate lubricants, a testing apparatus and procedure was developed to compare the 
candidate lubricants to phoscoating. In doing so, the candidates are ranked based on their performance during the test. Additionally, the following lubricant attributes are noted and compared from the experiments:

- Ease of application

- Coating adhesion

- Coating uniformity

- Coating quality

- Coefficient of friction.

In selecting candidate lubricants, the following aspects were considered:

- Generation of hazardous waste products

- Sludge

- Zinc

- High water usage

- Human exposure to toxic chemicals and fumes (if any)

- Energy consumption.

Note that the term "phoscoating" is used here to represent zinc phosphate coating based lubrication. This term will be used throughout this report.

\section{Approach}

The double cup backward extrusion test was used to evaluate the lubricants. The available single cup backward extrusion test at the ERC/NSM was retrofitted to suit the double cup backward extrusion test. The double cup backward extrusion test was chosen because:

- The test emulates severe deformation conditions similar to that occurring in actual forging operations

- The test is easy to conduct and lubricants can easily be ranked based on the difference in the cup heights.

The principle of this test is illustrated in Figure 7. The ratio of the cup heights, $\mathrm{H}_{1} / \mathrm{H}_{2}$, is an indication of lubricity. It has been found that the ratio of the cup heights increases as the friction factor increases. In other words, if there is no friction, the cup heights will be the same and the ratio, $\mathrm{H}_{1} / \mathrm{H}_{2}$, will be equal to one.

The container has a relative velocity to the upper punch, but not to the lower punch. Therefore, the material flow to the lower punch is more restricted. Thus, in the presence of friction, the height of the upper cup is larger than the height of the lower cup.

In Figure 7, $\mathrm{H}_{1}$ is the upper cup height and $\mathrm{H}_{2}$ is the lower cup height. The cup height ratio, $\mathrm{R}_{\mathrm{ch}}$, is defined by $\mathrm{H}_{1}$ divided by $\mathrm{H}_{2}$. This ratio is an indication of lubricity. If the friction factor increases, the cup height ratio will increase as well. In this test, however, FEM is used in combination with the experiments to determine the friction factor.

With the use of the commercial FEM code DEFORM, friction factor calibration curves (cup height ratio vs. stroke) can be established for different friction factor values $(m)$. By matching the cup height ratio and punch stroke obtained from experiments to that obtained from FE simulations, the friction factor of the lubricants can be obtained.

The following tasks were conducted in this study:

\begin{tabular}{|l|l|}
\hline Task 1 & $\begin{array}{l}\text { Survey of lubricants that can replace } \\
\text { phoscoating. }\end{array}$ \\
\hline Task 2 & $\begin{array}{l}\text { Determination of the flow stress of the } \\
\text { billet materials to be used for the tests. }\end{array}$ \\
\hline Task 3 & $\begin{array}{l}\text { Finite element simulation of the double } \\
\text { cup extrusion test in order to generate } \\
\text { friction factor calibration curves. }\end{array}$ \\
\hline Task 4 & $\begin{array}{l}\text { Design and manufacture the tooling for } \\
\text { the double cup extrusion test. ERC/NSM } \\
\text { tooling for the single cup backward } \\
\text { extrusion test was retrofitted to suite the } \\
\text { double cup backward extrusion } \\
\text { operation. }\end{array}$ \\
\hline Task 5 & $\begin{array}{l}\text { Test set up, specimen preparation, } \\
\text { lubricant application. Five lubricants } \\
\text { were used. }\end{array}$ \\
\hline Task 6 & $\begin{array}{l}\text { Double cup extrusion tests and } \\
\text { evaluation of results. }\end{array}$ \\
\hline
\end{tabular}




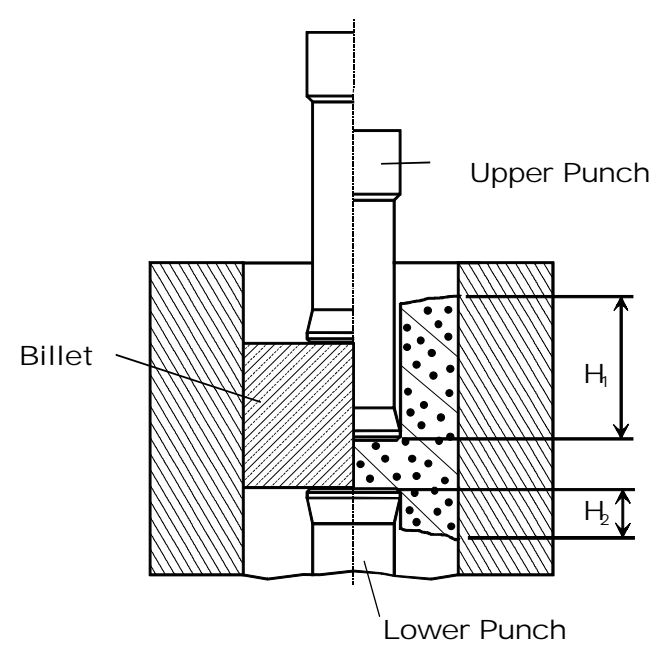

Figure 7. Double Cup Backward Extrusion Test

\section{Survey of Lubricants for} Replacement of Phoscoating

\section{Introduction}

The survey of cold forging lubricant manufacturers revealed four candidate lubricants for the replacement of phoscoating. These included: MEC HOMAT, Daido AquaLub, MCI Z-Coat, and Acheson. The following sections describe each of these lubricants.

\section{MEC HOMAT}

MEC International in Japan manufactures the MEC HOMAT lubricant. This lubricant is a water-based lubricant whose main components are metal compounds and organic sulfur compounds. This lubricant has the following advantages:

- Profitability-the installation space and the initial cost of the lubrication system are drastically reduced compared to phoscoating

- Waste-there is no waste disposal with this lubrication system as compared to the large amounts of sludge produced by a phoscoating system

- Productivity - the application of this lubricant only takes 5 minutes as compared of the phoscoating application, which takes 40 minutes

- Improvement of Work Environmentthere is no danger of strong alkali or strong acid with this lubrication system as compared to phoscoating

- Energy Savings - this lubrication system requires drying at $40^{\circ} \mathrm{C}$ as compared to phoscoating lubricant baths, which are heated to $90^{\circ} \mathrm{C}$.

\section{Daido AquaLub}

Daido Chemical Industries in Japan manufactures the Daido AquaLub lubricant. This lubricant has the following advantages:

- Profitability—the installation space and initial cost of the lubrication system are drastically reduced compared to phoscoating

- Waste-there is no wastewater disposal as compared to the large amounts of sludge produced by the phoscoating process

- Productivity - the application of this lubrication system is much easier than the application of a phoscoating

- Energy Savings - this lubrication system requires drying at room temperature as compared to phoscoating lubricant baths, which are heated to $90^{\circ} \mathrm{C}$.

\section{Metal Coating International (MCl) Z-Coat}

Metal Coatings International manufactures the Z-Coat lubricant. The Z-coat lubricant forms zinc/iron film on the surface of the billet. This film is porous and can be combined with forging oils, metal soaps, or molybdenum disulfide. The advantages of this lubricant are as follows:

- Profitability-the installation space and the initial cost of the lubrication 
system are drastically reduced

compared to phoscoating

- Waste-there is no wastewater disposal as compared to the large amounts of sludge produced by the phoscoating process

- Productivity - the application of this lubrication system is much easier than the application of a phoscoating

- Improvement of Work Environmentthere is no danger of strong alkali or strong acid with this lubrication system as compared to phoscoating

- Energy Savings - this lubrication system requires drying at room temperature as compared to phoscoating lubricant baths, which are heated to $90^{\circ} \mathrm{C}$

- Material Properties - this lubrication system does not degrade material properties as compared to phoscoating.

\section{Acheson}

No technical information was made available for the Acheson lubricant.

\section{Finite Element Simulations of the Double Cup Backward Extrusion Test}

\section{Introduction}

The aim of the simulations was to fully understand the parameters affecting the metal flow in the double cup backward extrusion process and to obtain friction factor calibration curves. The friction factor calibration curves would later be used to identify the fiction factor of the tested lubricants.

\section{General Conditions for the FE Simulations}

In order to get friction factor calibration curves, several simulations were conducted with
DEFORM. In the simulations, the constant shear friction model was used. The material properties of the billets (in the form of a power law $\sigma=K \varepsilon^{\mathrm{n}}$ ) for the simulations were obtained using the uniform compression test. The strength coefficient, $\mathrm{K}$, and strain hardening index, $\mathrm{n}$, obtained from the compression test for AISI 1038 and AISI 8620 are shown in Table 6.

The billet, with a height of $31.75 \mathrm{~mm}$ and a diameter of $31.75 \mathrm{~mm}$ (1.25 inches), was meshed with 1,500 elements. In order to simulate a $25 \mathrm{~mm}$ punch stroke, the stroke per step was set $0.25 \mathrm{~mm}$ and the 100 step were used. The shear friction factors used in the simulations were $\mathrm{m}=0, \mathrm{~m}=0.02, \mathrm{~m}=0.03$, $\mathrm{m}=0.04, \mathrm{~m}=0.05, \mathrm{~m}=0.055, \mathrm{~m}=0.06, \mathrm{~m}=0.065$, $\mathrm{m}=0.07, \mathrm{~m}=0.08, \mathrm{~m}=0.09, \mathrm{~m}=0.1$ and $\mathrm{m}=0.15$. Figure 8 shows the FEM model at two different punch strokes.

The cup height ratio, $\mathrm{R}_{\mathrm{ch}}$, is defined by Equation 4.1 and the real stroke, $S_{r}$, is defined by Equation 4.2 (Figure 9). This ratio is an indication of lubricity. The ratio of the cup heights increases as the friction factor increases. In other words, if there is no friction, the cup heights will be the same and hence the ratio, $\mathrm{H}_{1} / \mathrm{H}_{2}$, will be equal to one.

\section{FE Simulation Results and Discussion}

Figures 10 and 11 show the friction factor calibration curves for AISI 1038 and AISI 8610, respectively. The cup height ratio, $\mathrm{R}_{\mathrm{ch}}$, between the backward extrusion cup height, $\mathrm{H}_{1}$, and the forward extrusion cup height, $\mathrm{H}_{2}$, is plotted versus the punch stroke. The calibration curves can be used to approximate the friction factor for the double cup backward extrusion test using a particular lubricant.

Table 6. Material Properties Obtained from the Compression Test

\begin{tabular}{|c|c|}
\hline AISI 1038 & AISI 8620 \\
\hline $\mathrm{K}=140 \mathrm{ksi}, \mathrm{n}=0.15$ & $\mathrm{~K}=100 \mathrm{ksi}, \mathrm{n}=0.14$ \\
\hline
\end{tabular}



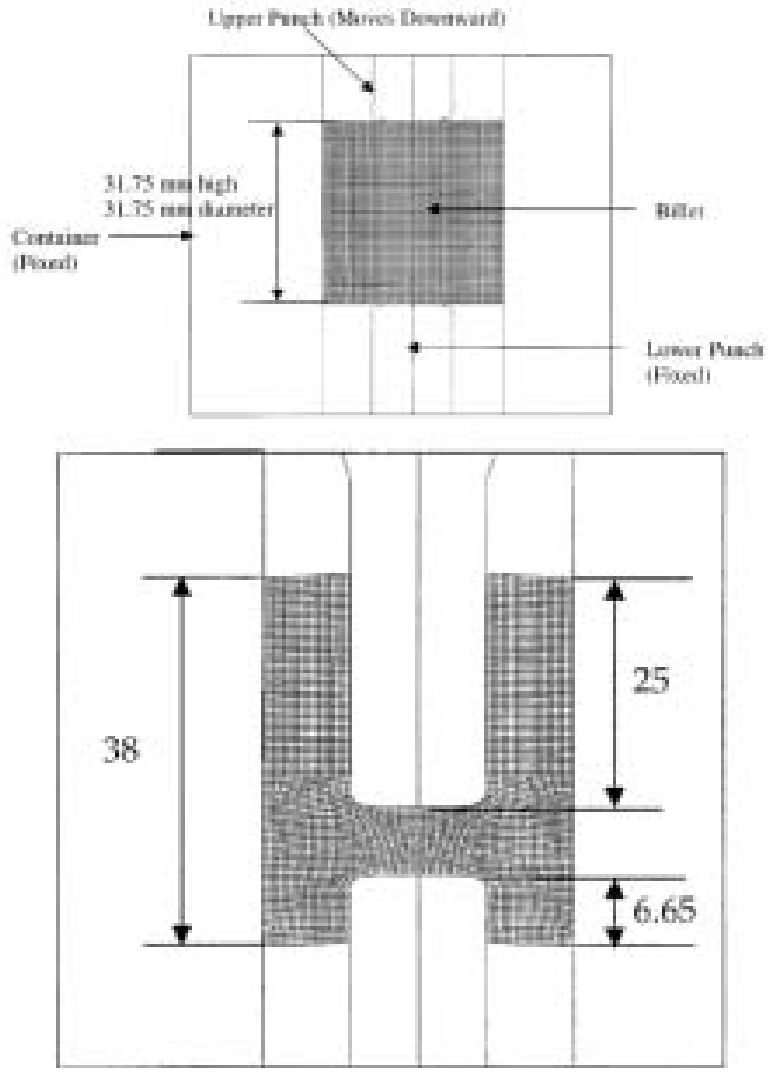

Figure 8. FE Model (Friction Factor $\mathbf{m}$ - 0.1)

It is shown that with increasing friction value " $m$ " the cup height ratio ratios increase as well. The figures also show that the cup height ratio increases with increasing stroke up to a maximum value $\left(\mathrm{H}_{2} / \mathrm{H}_{1}\right)$, and then gradually starts to decrease until a stroke of about $20 \mathrm{~mm}$ is reached. At this point, the cup height ratio becomes constant with increasing stroke for all friction factor values. Therefore, the best punch stroke to be used in the experiment should be beyond $20 \mathrm{~mm}$.

\section{Evaluation of Candidate Lubri- cants by Double Cup Backward Extrusion Test Using Tool Steel Punches}

\section{Introduction}

The double cup backward extrusion test is a method used to evaluate and compare lubri cants. It is used extensively in cold forging.
Basically, it is a combination of single cup forward and single cup backward extrusion processes. The test setup is shown in Figure 12. The container and the lower punch are fixed on the bed of the press and the upper punch is fixed on the ram of the press. In this test, the upper punch moves downwards while the bottom punch and the die are kept stationary. The diameters of both punches are the same. The upper cup is formed by a backward extrusion process and the lower cup is formed by a forward extrusion process. The simultaneous action of the two punches inside the cylindrical container generates the two cups.

The objective of the double cup backward extrusion test is to establish a correlation between the ratio of the extruded cup heights to the friction conditions between the billet surface and the punch and container. The friction conditions at the workpiece container interface are expressed as a number known as the friction factor, $\mathrm{m}$, which varies between 0 and 1 . If such a correlation can be established, then the existing friction conditions can be quantified.

The friction conditions at the containerworkpiece interface control the ratio between backward and forward extrusion (cup heights). Studies on friction conditions in cold forming with this test method have shown that the cup height ratio is extremely sensitive to the friction factor [Altan, et al. 1992], [Forcellese, A. et al. 1994]. It has also been shown that no significant influence of the initial sample geometry on friction exists [Barcellona, A. et al. 1996].

\section{Preparation of Specimens}

The experimental tests were conducted with two different materials. One was supplied by Metaldyne, and the other was supplied by Piper Impact. The Metaldyne material was an AISI 1038 grade carbon steel, whose composition is shown in Table 7. The Piper Impact material was AISI 8610 grade alloy steel, whose composition is shown in Table 8. 


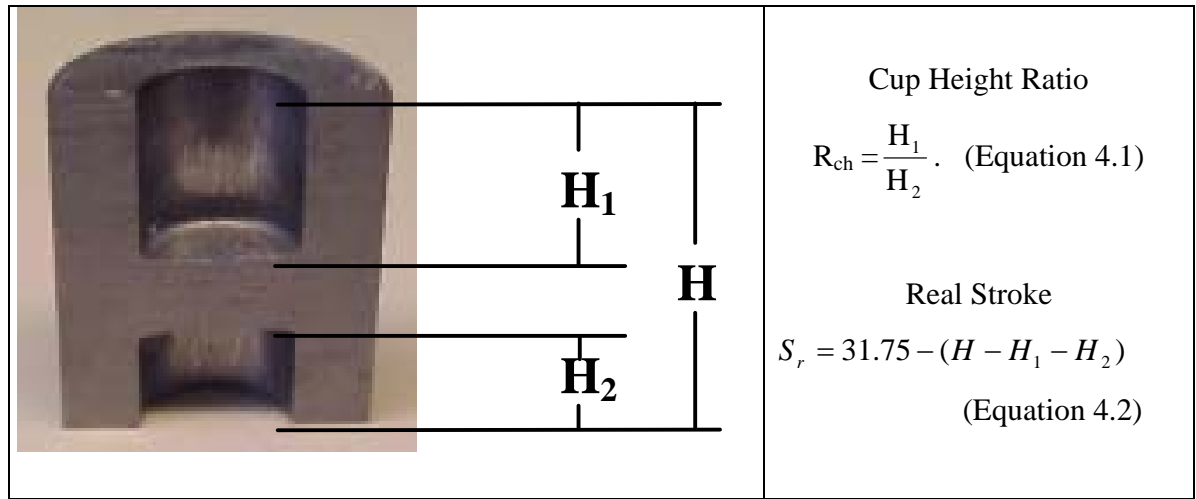

Figure 9. Definition of the Cup Height Ratio and Real Stroke

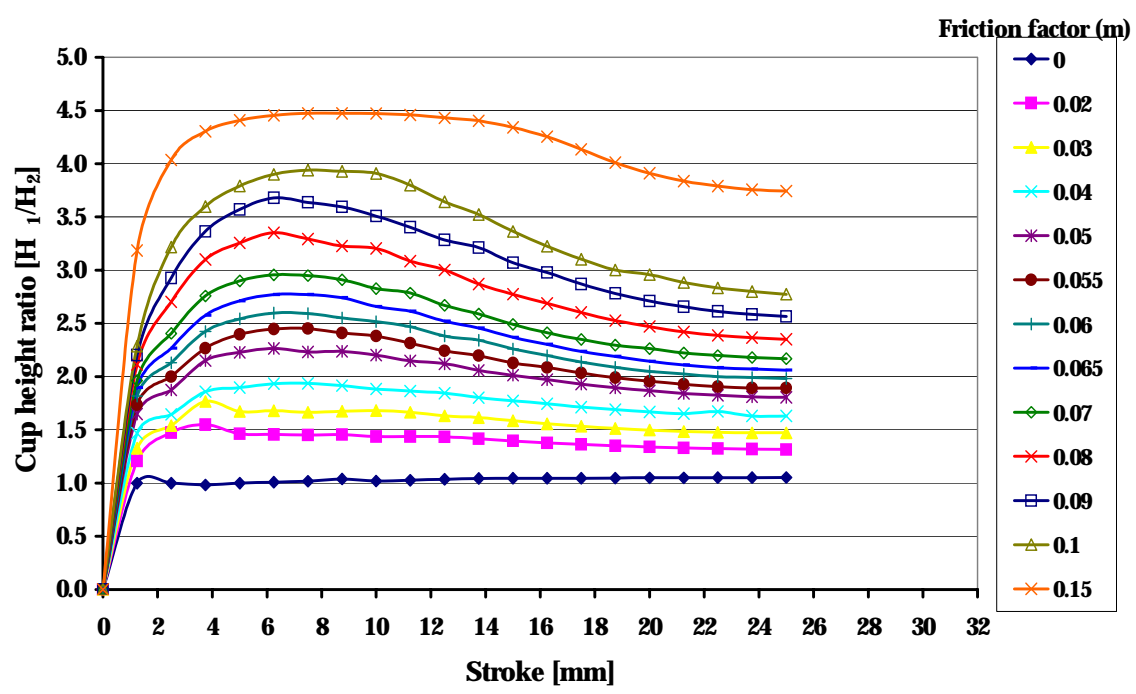

Figure 10. Friction Factor Calibration Curves (AISI 1038)

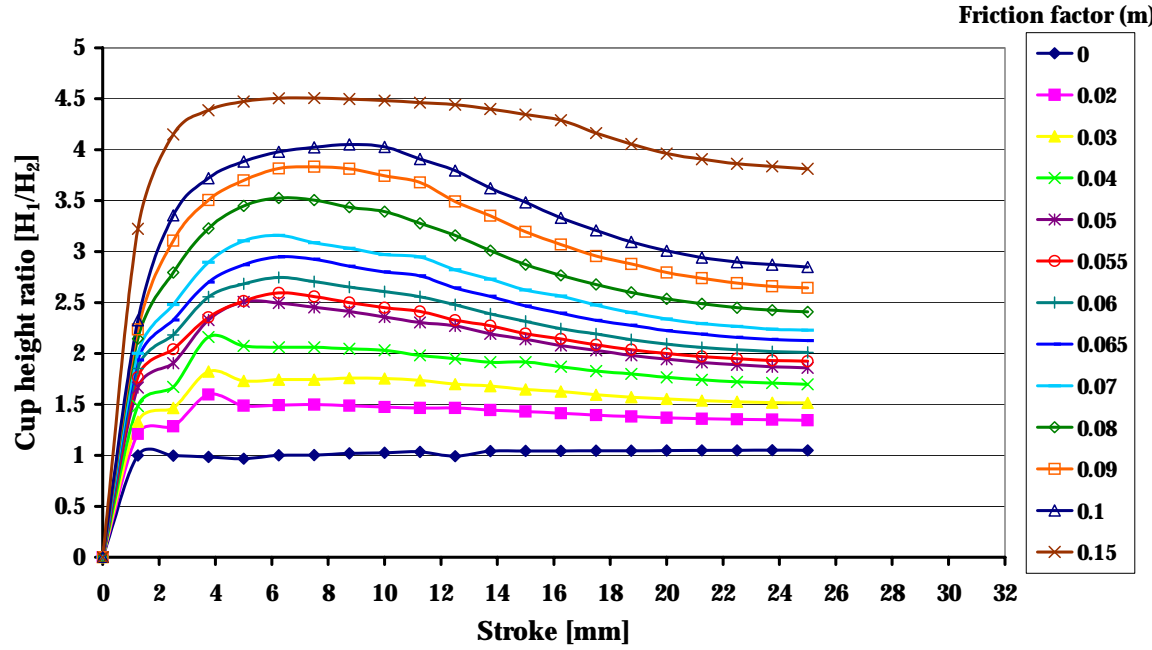

Figure 11. Friction Factor Calibration Curves (AISI 8610) 
Table 7. Chemical Composition of AISI 1038

\begin{tabular}{|c|c|c|c|c|}
\cline { 2 - 5 } \multicolumn{1}{c|}{} & $\mathbf{C ~ ( \% )}$ & Mn (\%) & $\mathbf{P}(\%)$ & $\mathbf{S}(\%)$ \\
\hline AISI & $0.32-0.38$ & $0.70-1.00$ & $\begin{array}{c}0.04 \\
\text { Max. }\end{array}$ & 0.05 \\
1038 & 0.30 &
\end{tabular}

Table 8. Chemical Composition of AISI 8610

\begin{tabular}{|c|c|c|c|c|c|c|}
\hline & $\begin{array}{c}C \\
(\%)\end{array}$ & $\begin{array}{c}\mathrm{Ni} \\
(\%)\end{array}$ & $\begin{array}{c}\mathrm{Cr} \\
(\%)\end{array}$ & $\begin{array}{l}\text { Mo } \\
(\%)\end{array}$ & $\begin{array}{l}M n \\
(\%)\end{array}$ & Si (\%) \\
\hline $\begin{array}{l}\text { AISI } \\
8610\end{array}$ & 0.1 & 0.55 & 0.5 & 0.25 & $\begin{array}{c}0.7- \\
0.9\end{array}$ & $\begin{array}{c}0.15- \\
0.3\end{array}$ \\
\hline
\end{tabular}

Specimens for a given material were obtained from the same rod. The rods were $31.75 \mathrm{~mm}$ in diameter and the specimens were cut to a length of $31.75 \mathrm{~mm}$.

\section{Application of Lubricants and Surface Characterization}

Four lubricants were applied on the billets made from AISI 8610, while only two lubricants were applied on the billets made from AISI 1038.

Table 9 summarizes this strategy.

The MEC HOMAT and Daido lubricants were applied by staff at the ERC/NSM while the
Table 9. Lubricants Used for the Tests

\begin{tabular}{|c|l|l|}
\hline $\begin{array}{c}\text { Lub } \\
\text { No. }\end{array}$ & \multicolumn{1}{|c|}{ Lubricant Name } & $\begin{array}{c}\text { Material Applied } \\
\text { To }\end{array}$ \\
\hline Lub 1 & Acheson & AISI 1038 \\
\hline Lub 2 & MEC HOMAT & AISI 8610 \\
\hline Lub 3 & Daido AquaLub & AISI 8610 \\
\hline Lub 4 & MCI Z-Coat & AISI 8610 \\
\hline Lub 5 & Phoscoating - Metaldyne & AISI 1038 \\
\hline Lub 6 & Phoscoating - Piper Impact & AISI 8610 \\
\hline
\end{tabular}

remaining lubricants were applied by the lubricant manufacturers. The following procedure was followed for the application of the MEC HOMAT lubricant:

- Agitated the lubricant until it was homogeneous and without trapped air bubbles

- Heat the lubricant to $40^{\circ} \mathrm{C}$

- Cleaned the billets with a standard degreasing agent

- Applied the lubricant to the billet with a brush

- Allowed the lubricant to dry on the billet.

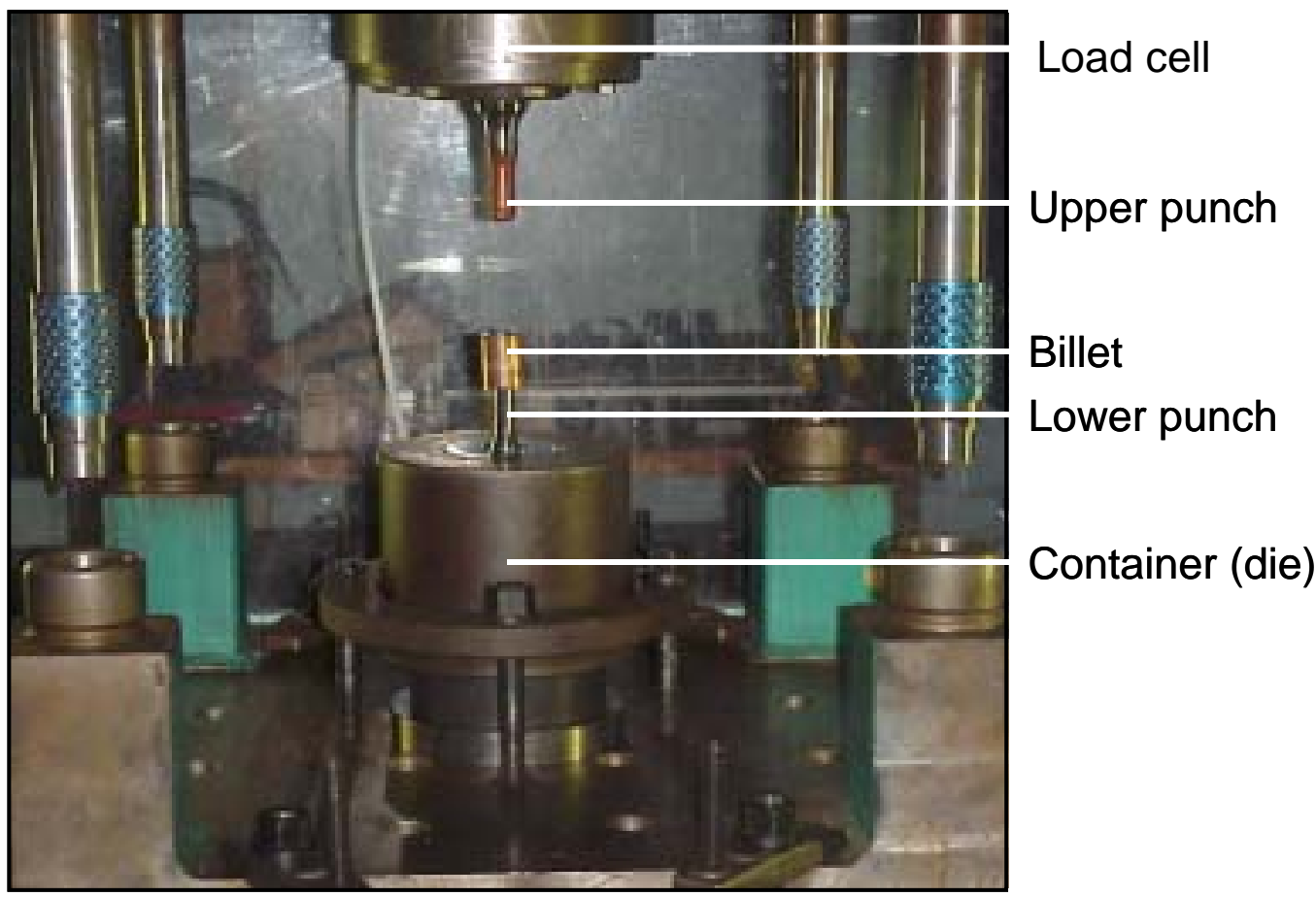

Figure 12. Double Cup Backward Extrusion Test Tooling 
The same procedure was followed for the application of the Daido lubricant except that it was applied at room temperature instead of $40^{\circ} \mathrm{C}$.

The following optical micrographs (Figure 13) compare the surfaces of the billets coated with the different lubricants before the tests. The widths of the micrographs are all equal. The micrographs show that for the most part, the lubricants coated the billets evenly. The specimens were also visually inspected. It was observed that the Acheson lubricant was not evenly applied.

\section{Experimental Setup}

Figure 12 shows the double cup backward extrusion tooling developed by the ERC/NSM and Figure 14 shows a 3D cross-sectional view of the tooling. The photograph shows the upper punch and the lower punch in their upper positions. Both the upper and lower punches were made from M2 tool steel material.

For the tests, a 200T load cell was used for load measurement and a laser sensor was used for stroke measurement. Data was obtained from these instruments with a data acquisition system utilizing a sample rate of 250 scans/second.

In order to convert the output voltage of the load cell and the laser sensor to force and press stroke respectively, calibration was performed. Stroke calibration was performed by moving the press to different heights and noting the output from the laser sensor. Then, a graph of voltage vs. stroke was made in order to produce a calibration curve for the laser sensor. The stroke heights recorded were in the range where actual extrusion takes place. Load cell calibration was performed by balancing the strain gauge bridge configuration in the load cell and then connecting a shunt resistor simulating the load capacity of sensor. The recorded voltage was correlated to the load capacity and a calibration factor was obtained [Wenning, et al. 2002]. These proce- dures were repeated every day a new test was conducted.

\section{Determination of Appropriate Punch Stroke}

The variation of the cup height ratio with increasing stroke limited the minimum stroke to $20 \mathrm{~mm}$. In addition, the billet height of 31.75 $\mathrm{mm}$ limited the maximum stroke to a approximately $28 \mathrm{~mm}$. Because the performance of each lubricant varied for stroke lengths between 20 and $28 \mathrm{~mm}$, the best stroke length for comparison of the lubricants was evaluated. For this evaluation, trial experiments were conducted for the strokes of approximately $27,25,23$, and $21 \mathrm{~mm}$.

The results of this investigation showed that at higher strokes (i.e., $27 \mathrm{~mm}$ ) the billet coated with MEC HOMAT fractured (Figure 15). This fracture was due to the fact that as the material flows upwards to form the upper cup and downwards to form the lower cup, a region of velocity discontinuity can be formed. This phenomenon can occur if a certain maximum punch stroke is reached and this limiting stroke is a function of how good the lubricant is. Finite element simulation was used to confirm this phenomenon (Figure 16). The FE simulations show that the damage value on the surface of the billet with the lower friction factor value is higher than the damage value on the surface of the billet with the higher friction factor value. When the friction is low, the material flows almost equally in the forward extrusion and backward extrusion directions, thus leading to high surface expansion and rupture at the surface. However, by reducing the stroke, this effect can be prevented. A similar trend was observed with a stroke of $25 \mathrm{~mm}$; however, no cracks were observed with a stroke of $21 \mathrm{~mm}$. Because cracks will lead to errors in the determination of the shear friction factor of the lubricant a stroke of $21 \mathrm{~mm}$ was chosen for the experiments. 


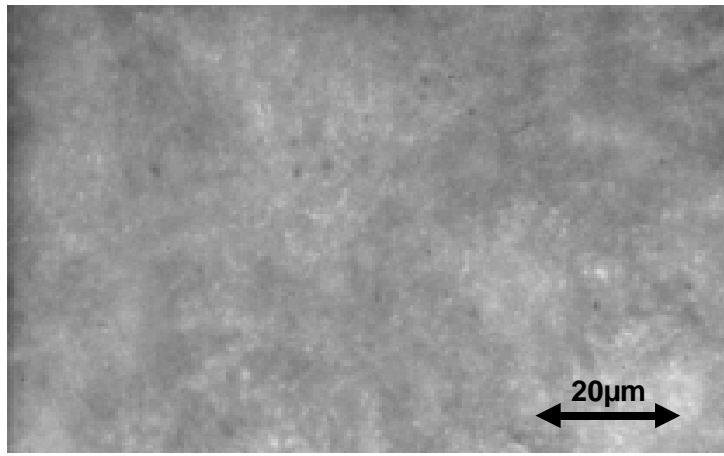

AISI 8610 billet lubricated with Piper Impact Phoscoating

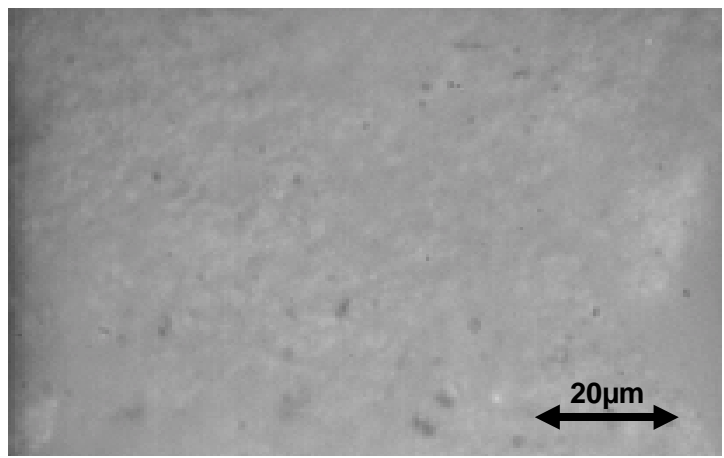

AISI 8610 billet lubricated with MEC HOMAT

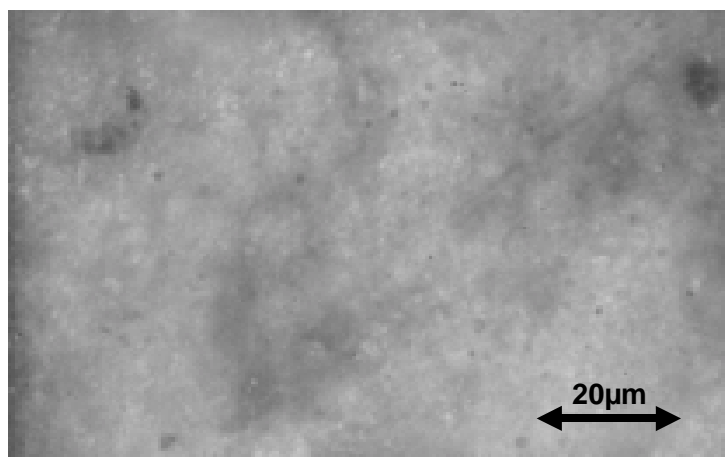

AISI 1038 billet lubricated with Metaldyne Phoscoating

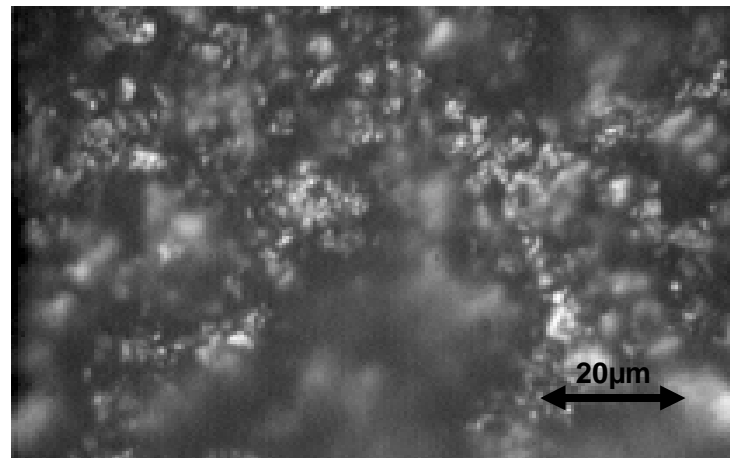

AISI 8610 billet lubricated with $\mathrm{MCI}$ Z-Coat

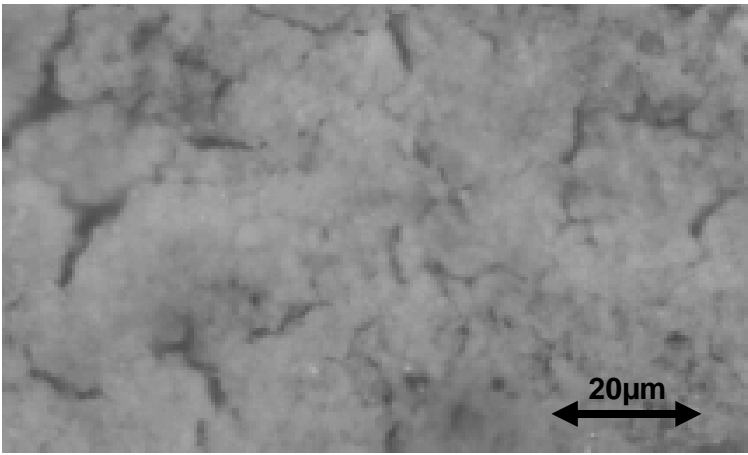

AISI 8610 billet lubricated with Daido AquaLub

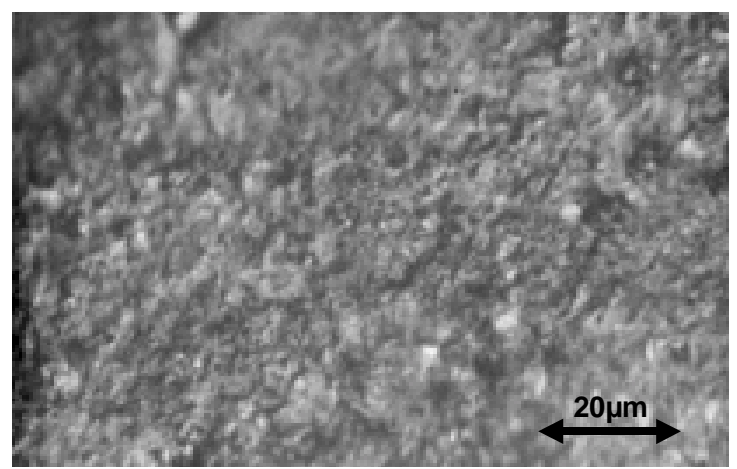

AISI 1038 billet lubricated with Acheson lubricant

Figure 13. Optical Micrographs of Lubricated Billet Surfaces Before Tests

\section{Tests}

The tests were conducted using a 160-ton hydraulic press with a ram speed of $10 \mathrm{~mm} / \mathrm{second}$ and a $21 \mathrm{~mm}$ punch stroke. The experimental matrix is shown in Table 10. The punch load was measured using a load cell; the stroke was measured using a laser sensor. Directly following each test, a thermocouple was used to measure the temperature inside the upper cup of the extruded billet. Also the die and the punches were cleaned and checked for galling or scratching in order to insure the same conditions existed for every test. After the cup temperature reached room temperature, the cup height ratio and real stroke were calculated easuring the upper and lower cup heights, as well as the total extruded part height with a caliper (Figure 9). Finally, the cup height ratio and the stroke obtained from the experiment were matched with the cup height ratio and the stroke obtained from FE simulation to determine the friction factor $\mathrm{m}$. 


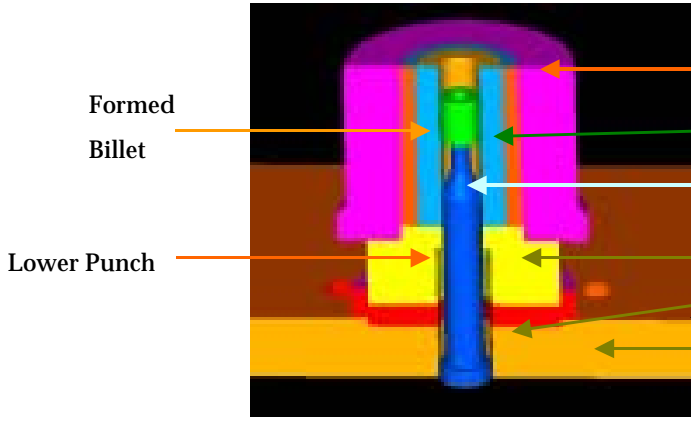

Liner

Dielnsert

Guide Plate

Adjusting plate

Bottom

Bolster

Figure 14. Double Cup Backward Extrusion Tooling: 3D Cross-Section View

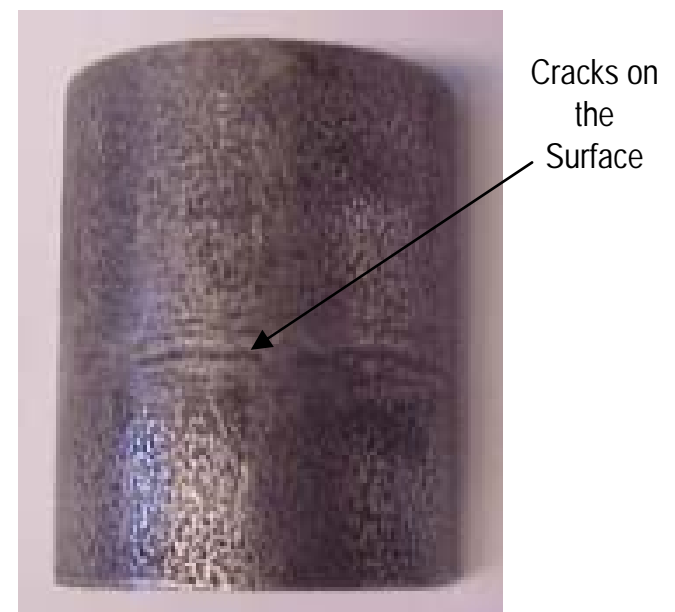

Figure 15. Surface Cracks in Billets Coated with MEC HOMAT at $27 \mathrm{~mm}$ Stroke

Table 10. Experimental Matrix for the Double Cup Backward Extrusion Test

\begin{tabular}{|c|l|c|c|}
\hline Lub No. & Lubricant Name & $\begin{array}{c}\text { Material Applied } \\
\text { To }\end{array}$ & No. of Specimens \\
\hline Lub 1 & Acheson & AISI 1038 & 20 \\
\hline Lub 2 & MEC HOMAT & AISI 8610 & 20 \\
\hline Lub 3 & Daido AquaLub & AISI 8610 & 20 \\
\hline Lub 4 & MCI Z-Coat & AISI 8610 & 20 \\
\hline Lub 5 & Phoscoating - Metaldyne & AISI 1038 & 20 \\
\hline Lub 6 & Phoscoating - Piper Impact & AISI 8610 & 20 \\
\hline
\end{tabular}

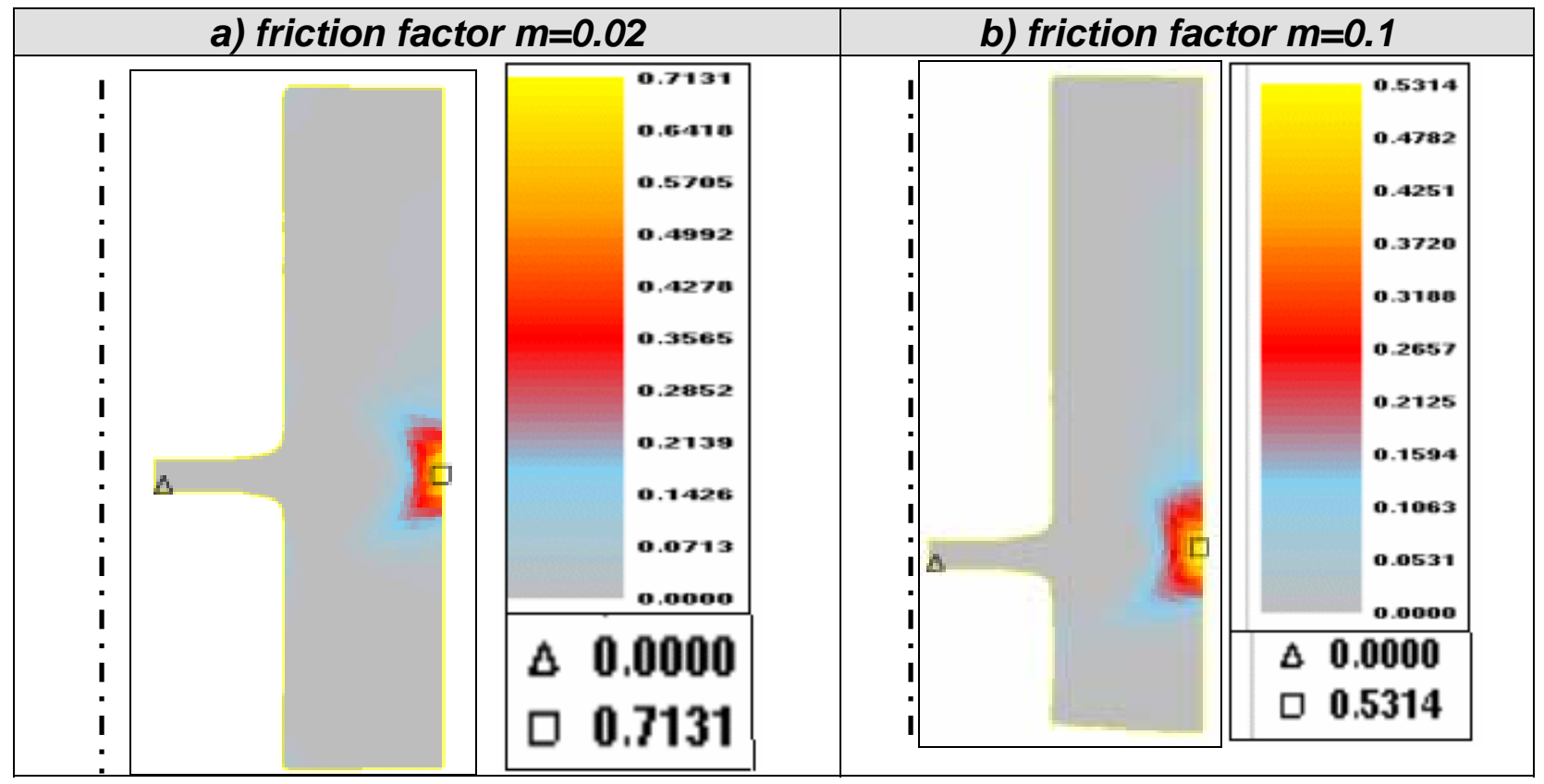

Figure 16. Damage Value Distribution in Double Cup Extrusion for Low and High Friction 
In addition, optical micrographs of the specimens were taken after the tests in order to further evaluate the performance of the lubricants. To obtain micrographs from within the cups, the forged billets were cut into two halves. Figures $17 \mathrm{a}$ and $17 \mathrm{~b}$ show the photographs of selected extruded parts.

\begin{tabular}{|c|c|c|c|}
\hline Lub & Original Billet & Extruded Part & $\begin{array}{c}\text { Extruded Part } \\
\text { (Cross Section) }\end{array}$ \\
\hline $\begin{array}{c}\text { Phoscoating } \\
\text { Piper }\end{array}$ & & & \\
\hline & & & \\
MEC & & & \\
HOMAT & & & \\
\hline & & \\
\hline
\end{tabular}

Figure 17a. Photographs of Selected Extruded Parts (AISI 8610) 


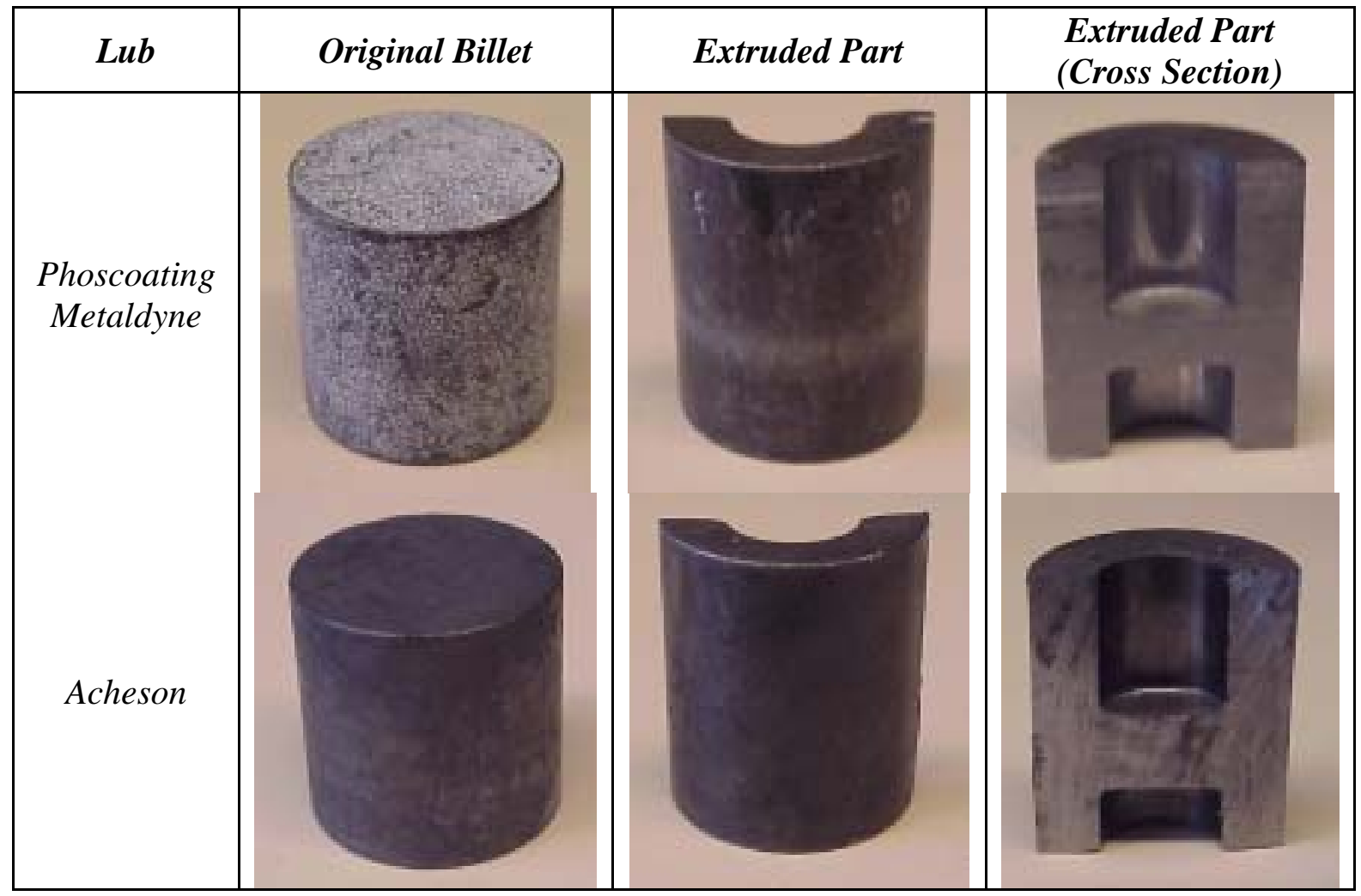

Figure 17b. Photographs of Selected Extruded Parts (AISI 1038)

\section{Results and Discussion \\ Performance Comparison of the Tested Lubricants}

All of the load versus stroke curves show the same trend. There is a rapid increase in load up to $50 \mathrm{U} . \mathrm{S}$. tons at a $12 \mathrm{~mm}$ stroke and then the load slowly decreases with increasing stroke up to $21 \mathrm{~mm}$. Therefore, the load cannot be used to evaluate the performance of the lubricants. Also, because the temperature induced in the billet did not show a clear, measurable dependence on the lubricant used, it cannot be used to evaluate the performance of the lubricants either.

To establish a ranking of the lubricants, lubricant performance diagrams were made. With these diagrams, the cup height ratios, $R_{c h}$, are plotted on the ordinate and the friction factor is plotted on the abscissa. The value of the cup height ratio is read from the lower position of the data range, whereas the value of the friction factor is read from the upper position of each data range. It should be noted that these values are an average from the 20 samples. The aim of a successful double cup extrusion operation is to reach processes with a minimum cup height ratio at a minimum friction factor. Therefore, in this diagram, the lubricant with the best performance is located closest to the origin.

In Figure 18, the lubricant performance diagram for the four lubricants used with the Piper Impact material (AISI 8610) is illustrated. Within this chart, it can be identified very easily that the best results were obtained with MEC HOMAT, followed by Daido AquaLub.

The aim of these tests was to find lubricants that were able to replace the conventional phoscoating. Both lubricants, MEC HOMAT and Daido AquaLub, obtained better cup height ratios and friction factors than phoscoating. MEC HOMAT 
reduced the cup height ratio, $\mathrm{R}_{\mathrm{ch}}$, in comparison to the phoscoating about $30 \%$, from 2.25 to 1.6 , and the friction factor about $45 \%$, from 0.065 to 0.035. Daido AquaLub decreased the cup height ratio about $25 \%$, and the friction factor about $40 \%$. MCI Z-Coat did not perform better than phoscoating. For further clarification, these results are shown in Figure 19 in bar graph format.

Figure 20 shows the lubricant performance diagram and Figure 21 shows a bar graph for the lubricants used with the AISI 1038 material. Phoscoating performed better than Acheson lubricant. The average cup height ratio from experiments conducted with the Acheson lubricant is $10 \%$ higher than the experiments conducted with phoscoating. Also, the friction factor increases $25 \%$, from 0.050 to 0.065 .

As shown in Figures 22 and 23, a large range of cup height ratios was observed with the Acheson lubricant as compared to MEC HOMAT. This indicates a large variation in the parameters affecting friction for the Acheson lubricant tests. Visual observation of the billets coated with the Acheson lubricant revealed that the lubricant was not evenly applied on the surface. This may have been the cause of the large cup height ratio variation observed in Figure 22.

Figures $24-29$ show the optical micrographs taken after the tests in order to compare the surfaces of the billets when extruded with each lubricant. These micrographs were taken by an optical microscope in the upper cup, lower cup, and on the outside surface on the positions shown. With the AISI 8610 extruded billets, MEC HOMAT and phoscoating show remains of lubricant in the upper cup; however, small scratches are also observed. Contrary to these lubricants, MCI Z-Coat leads to deep scratches in the upper cup. In the lower cup, where the surface enlargement is smaller, MEC HOMAT, Daido AquaLub, and phoscoating perform very well. There are few scratches observed. MCI ZCoat again leads to deeper scratches. Thus, the lubricants with the lowest friction factors also attained the best surface qualities. With the AISI 1038 extruded billets, the Acheson lubricant shows no areas of lubricant remaining. The Acheson lubricant also shows more scratches in the upper cup than phoscoating (Figure 27).

\section{Evaluation of Candidate Lubricants by Double Cup Backward Extrusion Test Using Carbide Punches}

\section{Introduction}

In order to further evaluate the candidate lubricants, a series of double cup backward extrusion tests were conducted at the Kinefac Corporation. The geometry of the forming tooling was identical to that used by the ERC/NSM; however, the punches were made from carbide as opposed to M2 tool steel. In addition, the Kinefac Corporation was able to incorporate two punch coatings, namely TiN and TiAlN + WCC, into their tests.

\section{Preparation of Specimens}

The experimental tests were completed with billets of one material, namely AISI 1038. This material was spherodized annealed. The dimensions of the billets were $31.75 \mathrm{~mm}+/$ $.254 \mathrm{~mm}$ diameter and $31.75 \mathrm{~mm}+/-.254 \mathrm{~mm}$ length. The ends were sawed and the billets were tumbled to remove burrs and sharp edges. 


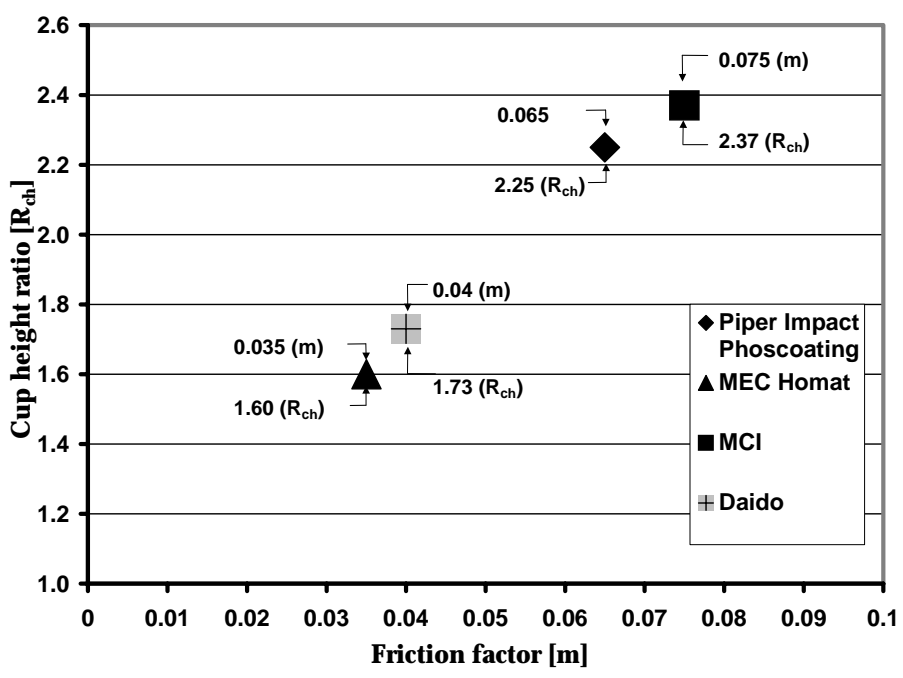

Figure 18. Lubricant Performance as a Function of Cup Height Ratio and Friction Factor (AISI 8610)

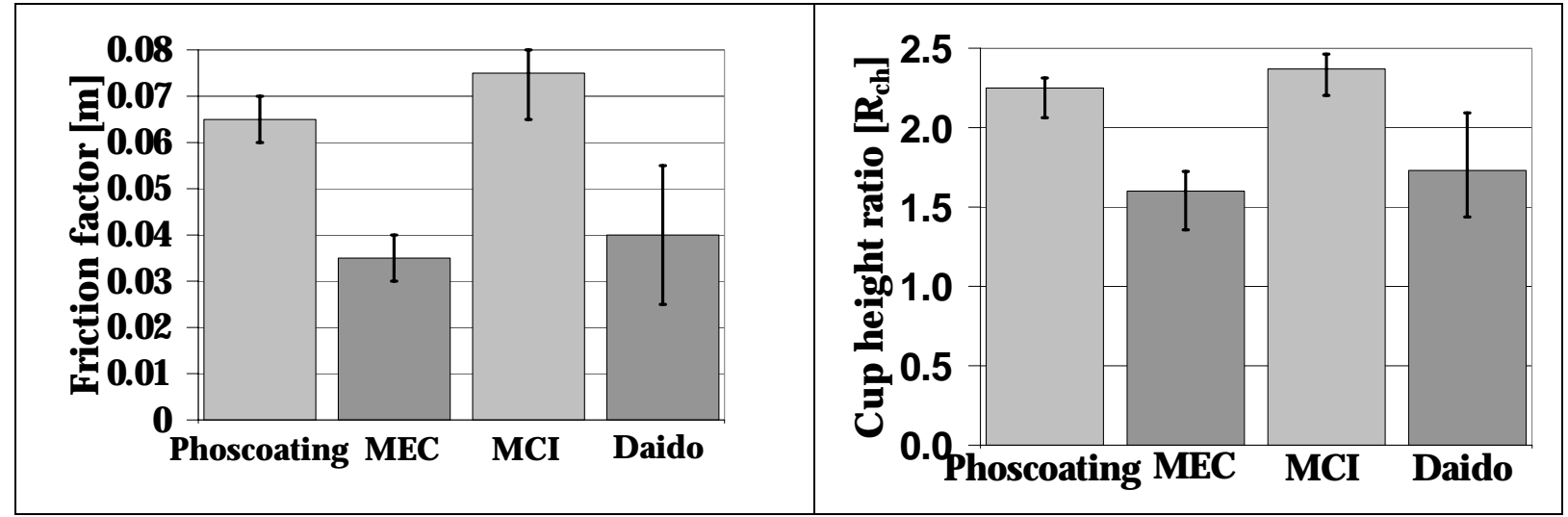

Figure 19. Bar Graph for Lubricants Used with AISI 8610

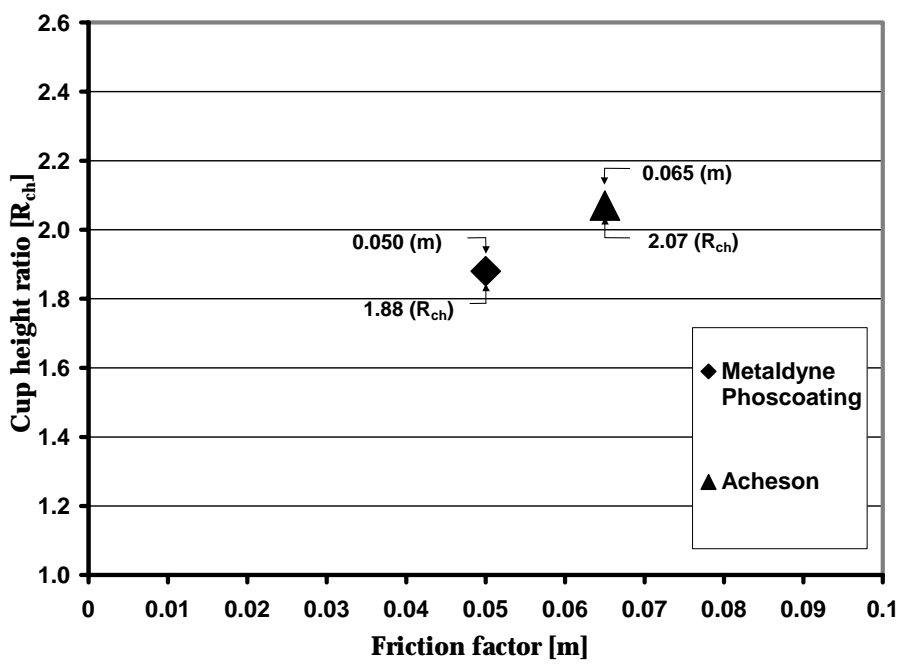

Figure 20. Lubricant Performance as a Function of Cup Height Ratio and Friction Factor (AISI 1038) 


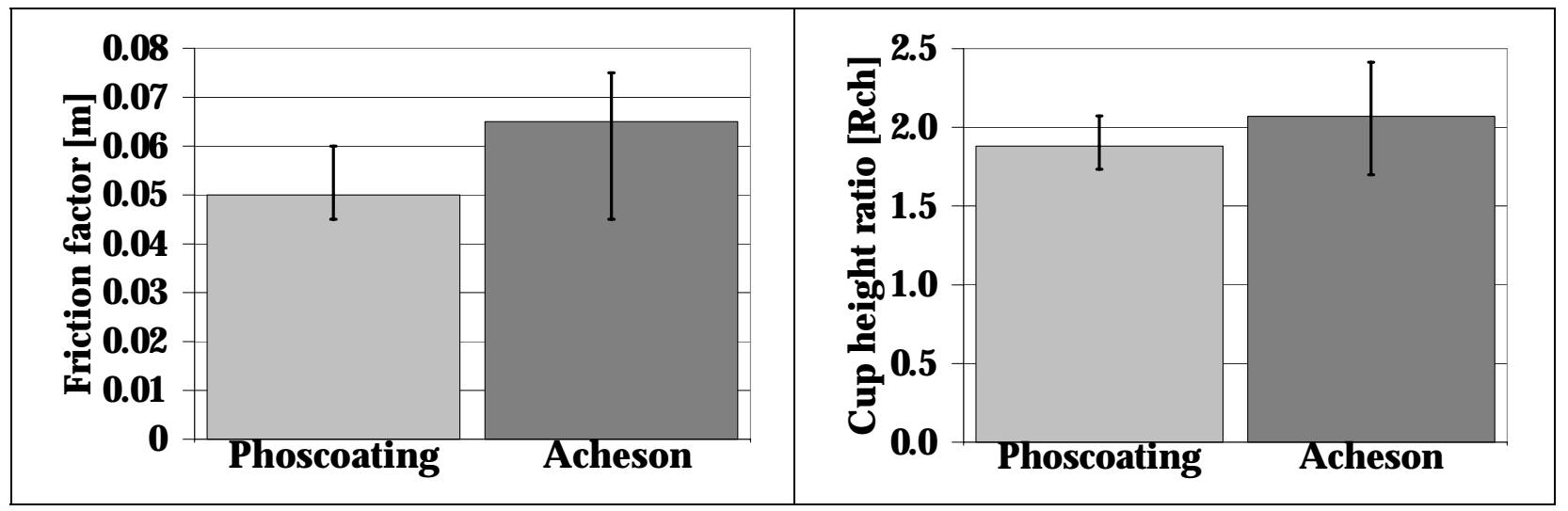

Figure 21. Bar Graph for Lubricants Used with AISI 1038

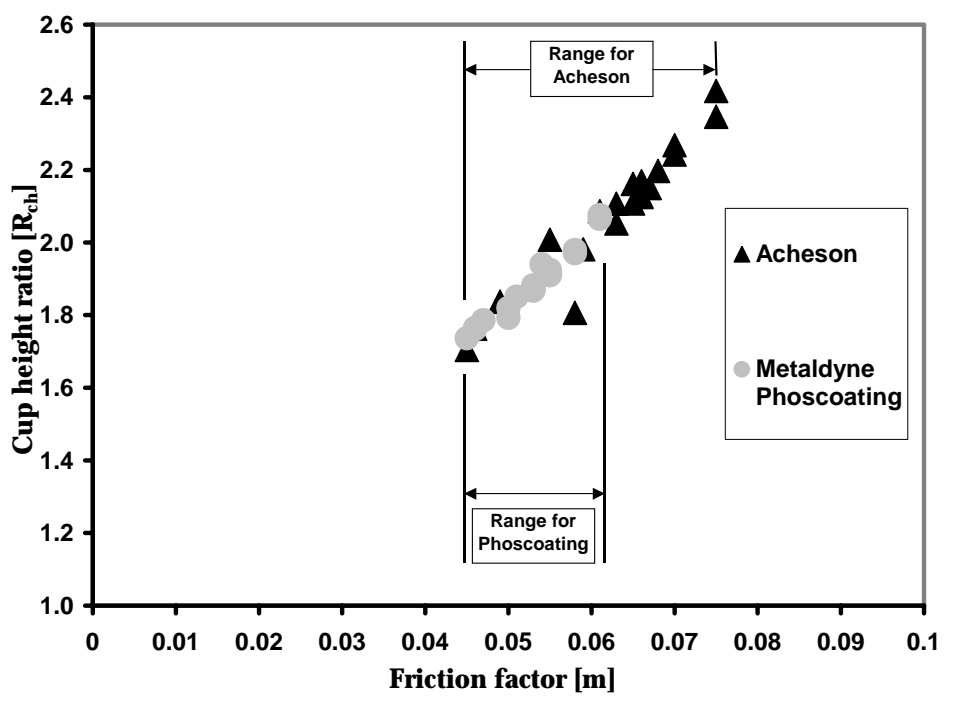

Figure 22. Performance Comparison Between Acheson and Phoscoating Lubricants

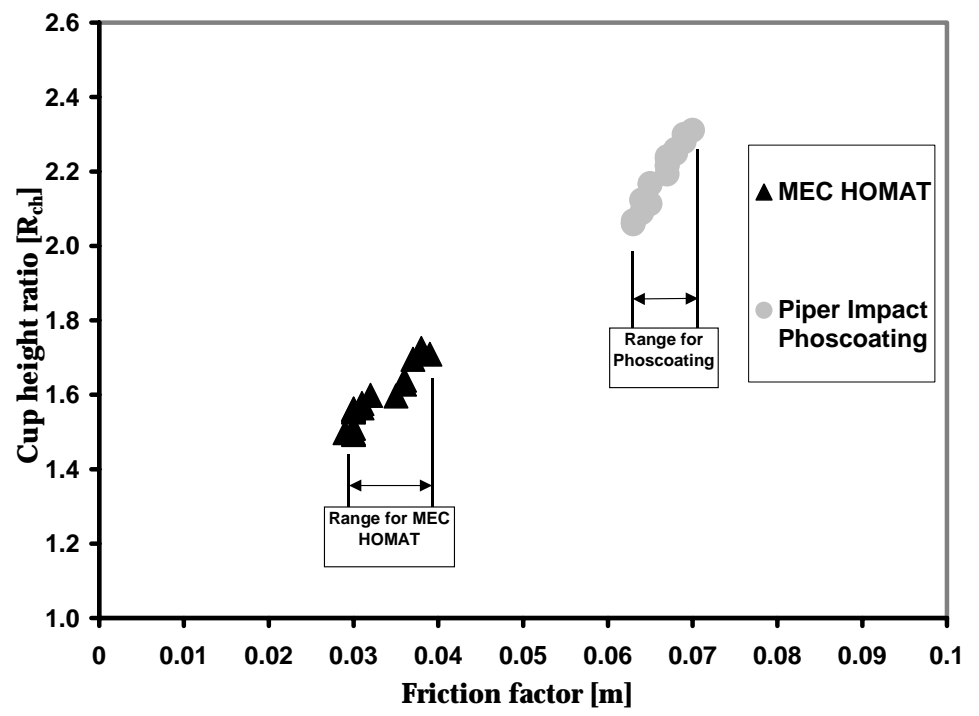

Figure 23. Performance Comparison Between MEC HOMAT and Phoscoating Lubricants 


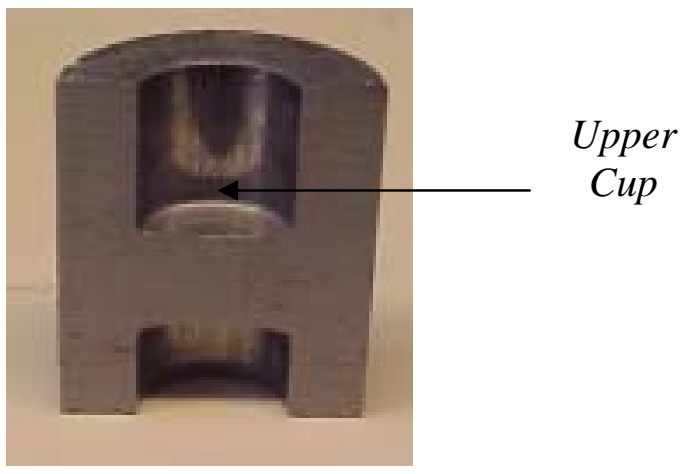

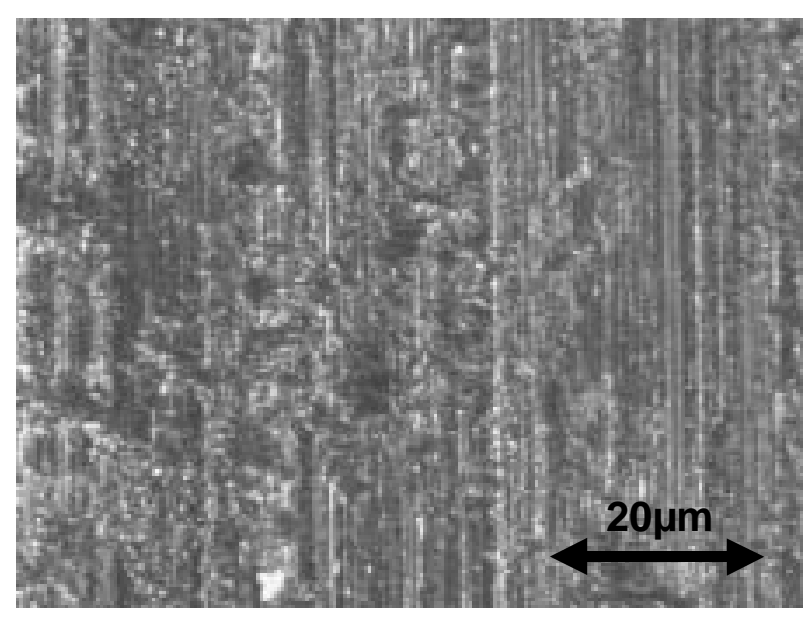

Phoscoating - Piper Impact

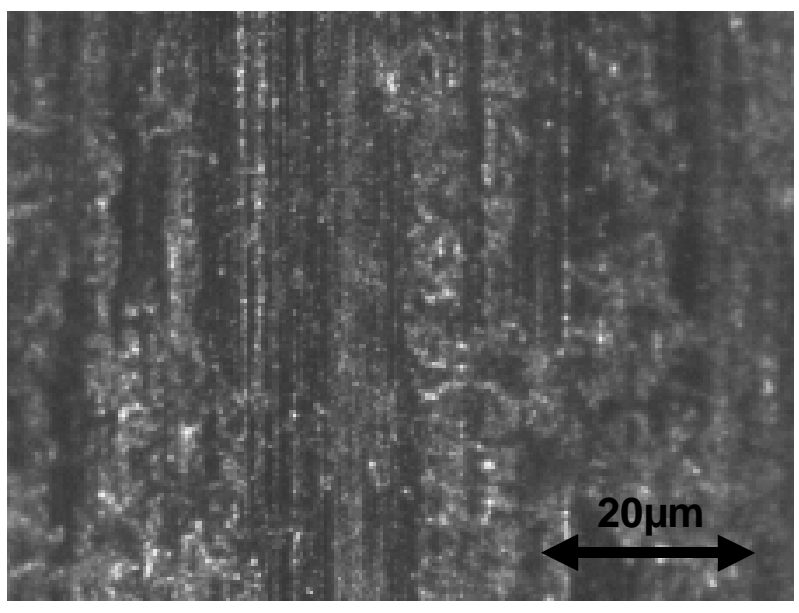

MEC HOMAT

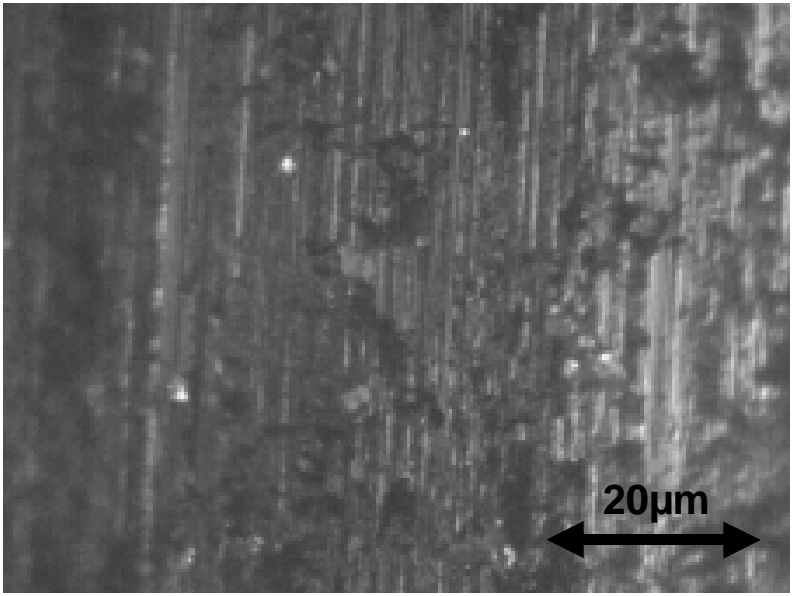

Daido AquaLub

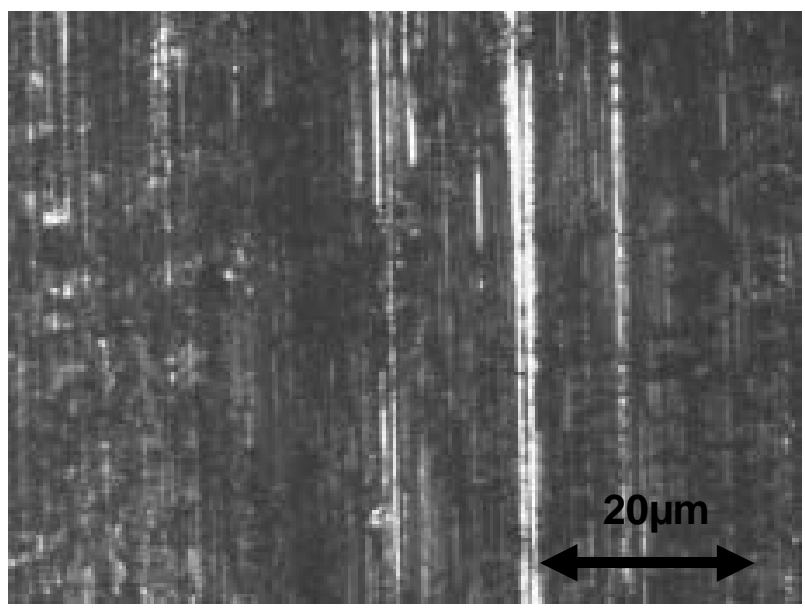

$\mathrm{MCl}$ Z-Coat

Figure 24. Optical Micrographs After Tests in the Upper Cups (AISI 8610) 


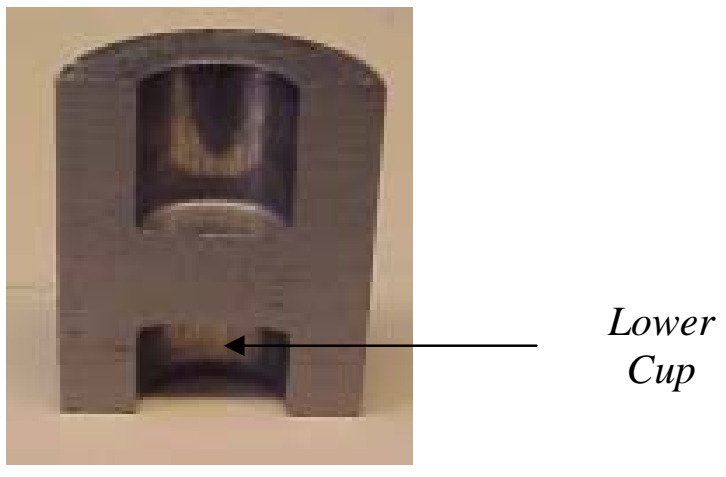

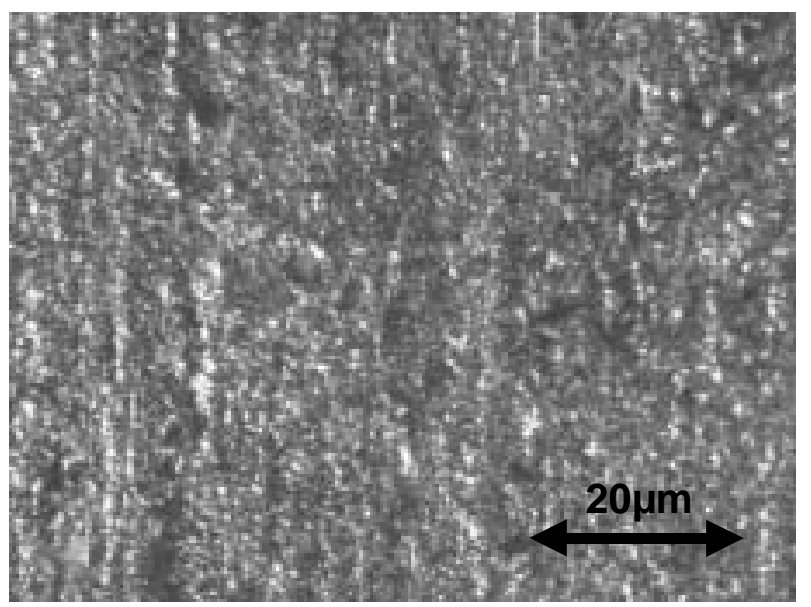

Phoscoating - Piper Impact

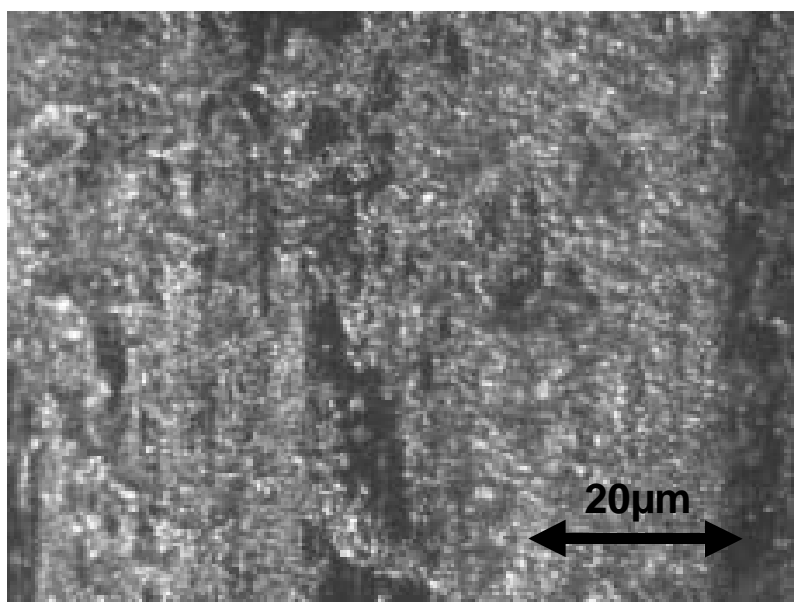

MEC HOMAT

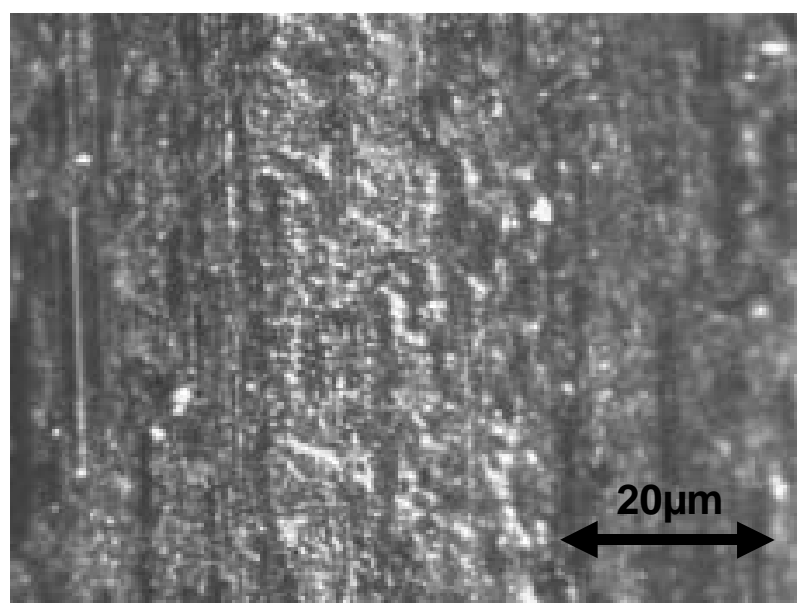

Daido AquaLub

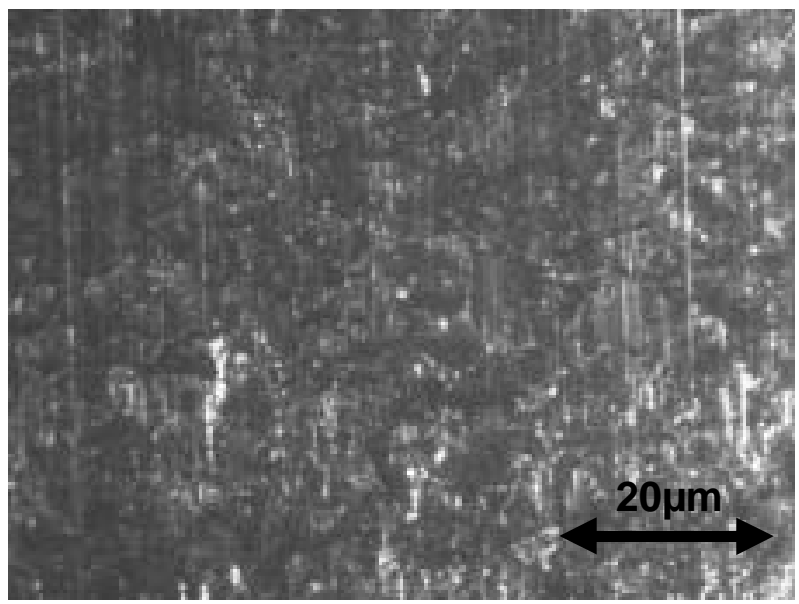

MCI Z-Coat

Figure 25. Optical Micrographs After Tests in the Lower Cups (AISI 8610) 


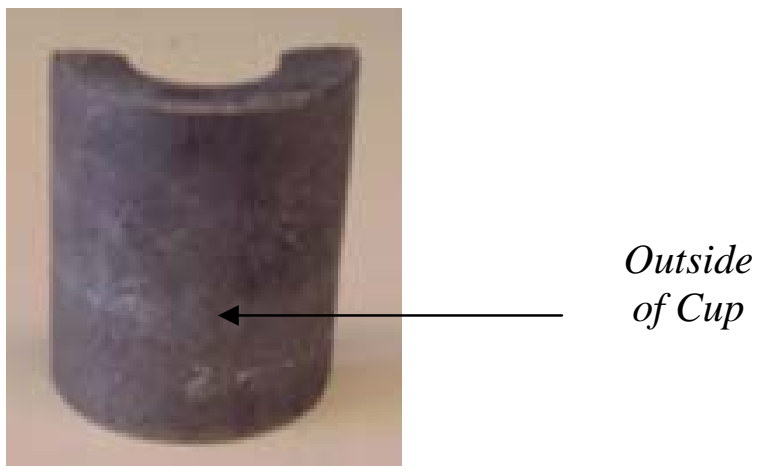

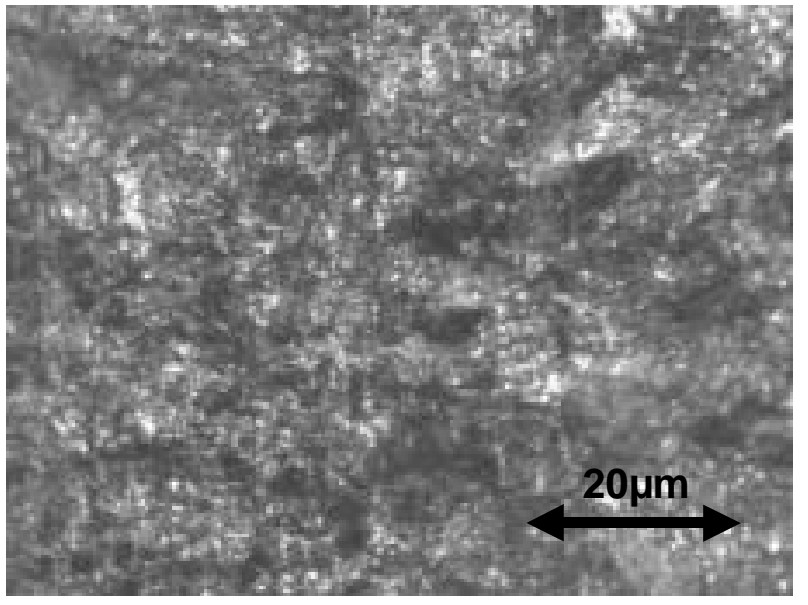

Phoscoating - Piper Impact

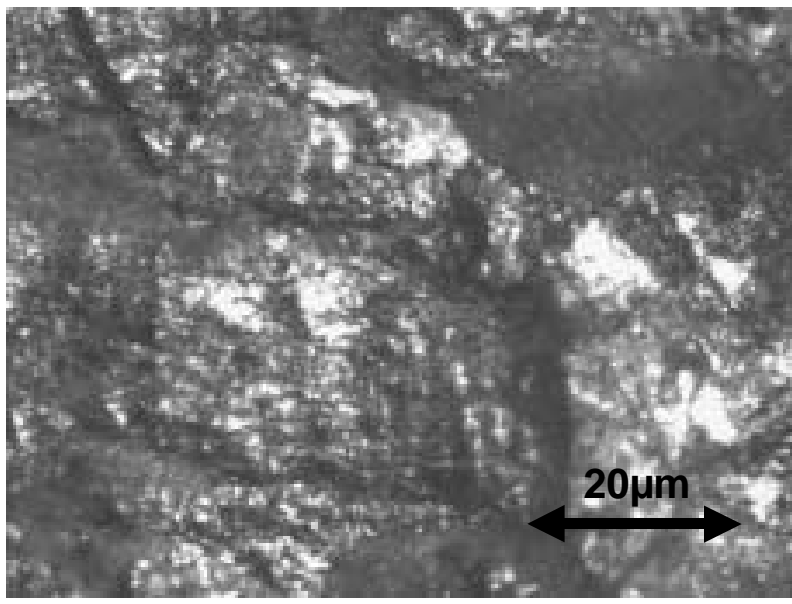

MEC HOMAT

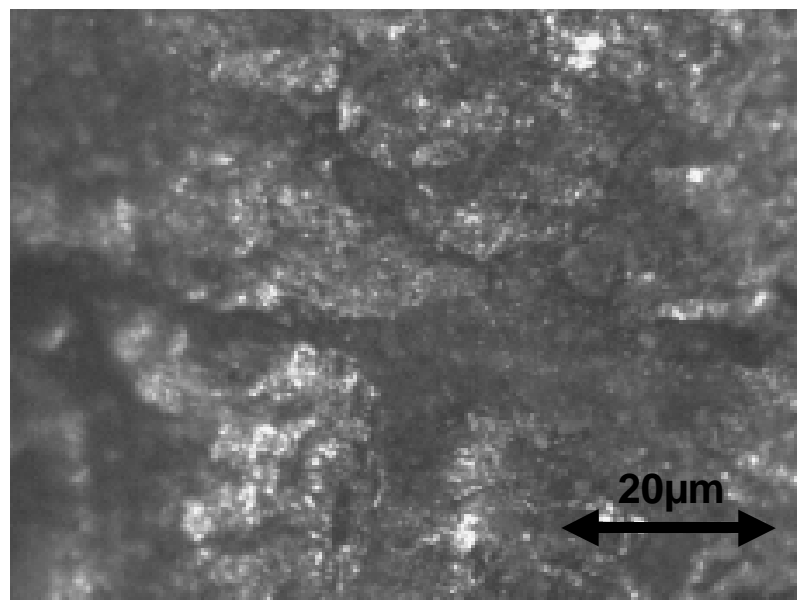

Daido AquaLub

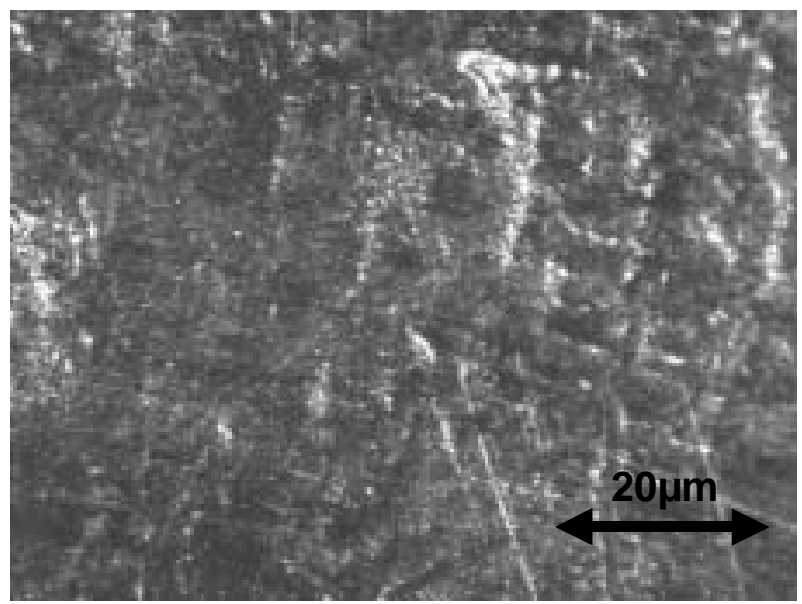

MCl Z-Coat

Figure 26. Optical Micrographs After Tests at the Outside Surface (AISI 8610) 


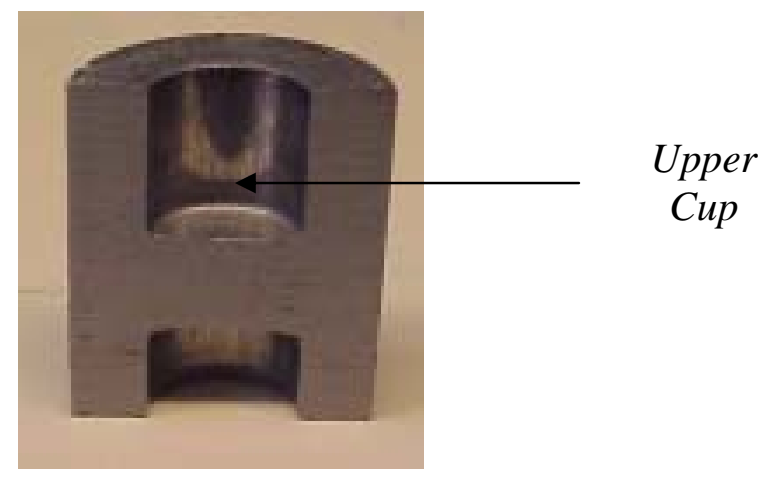

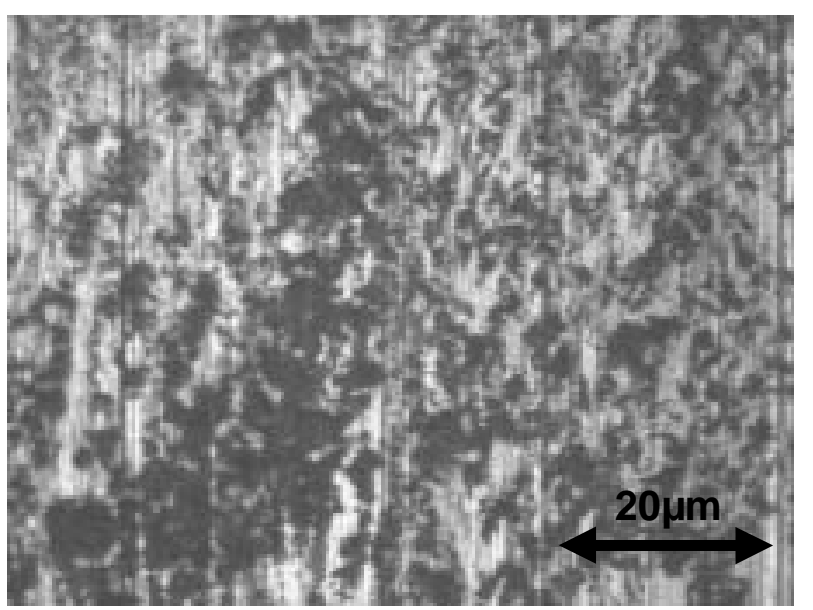

Phoscoating - Metaldyne

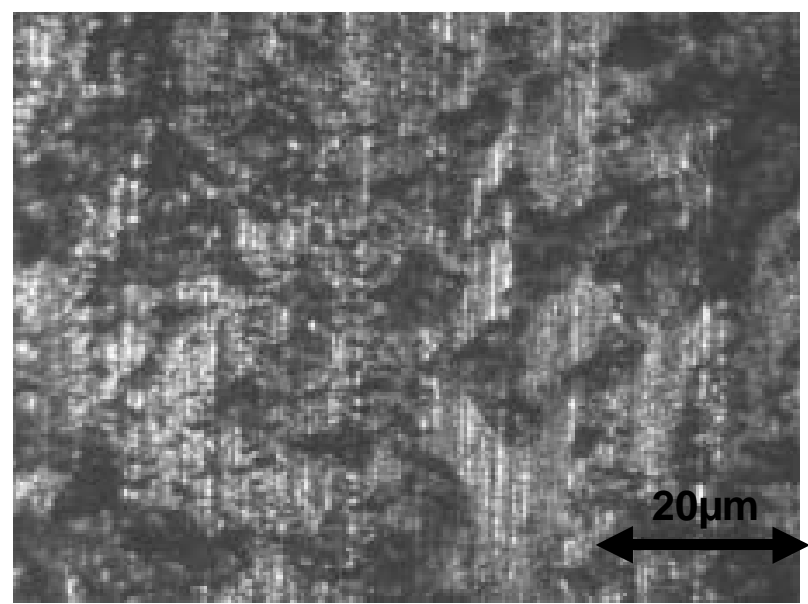

Acheson

Figure 27. Optical Micrographs After Tests in the Upper Cups (AISI 1038) 


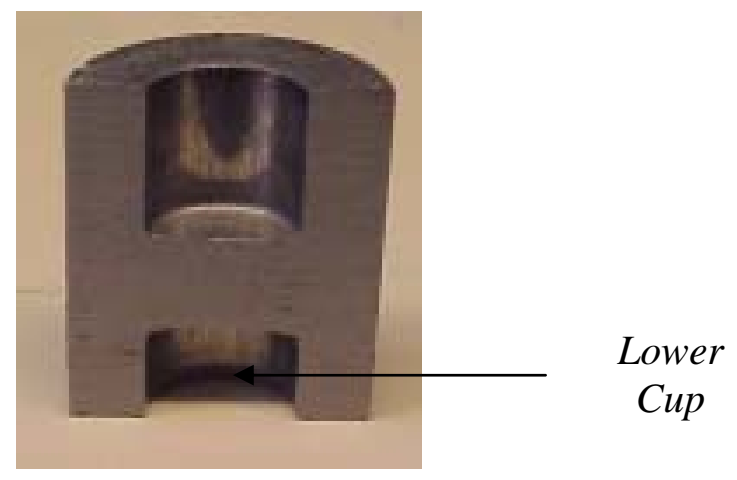

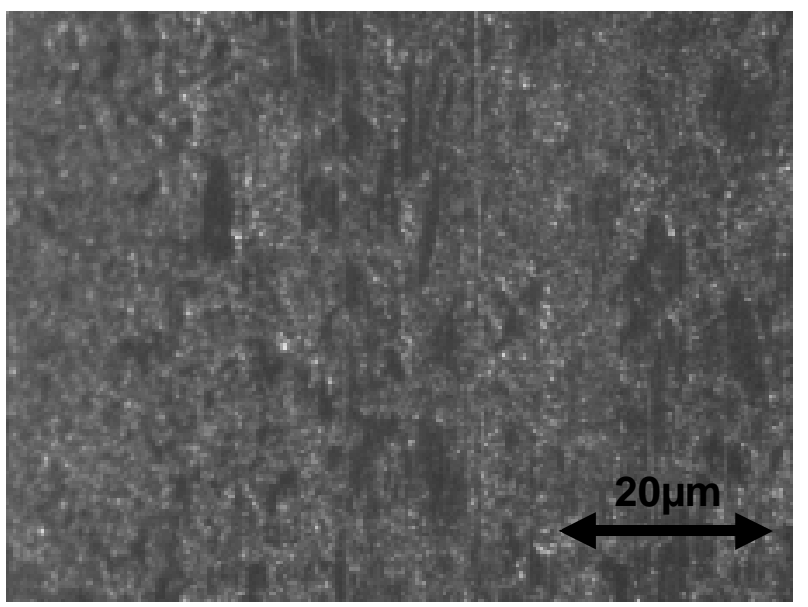

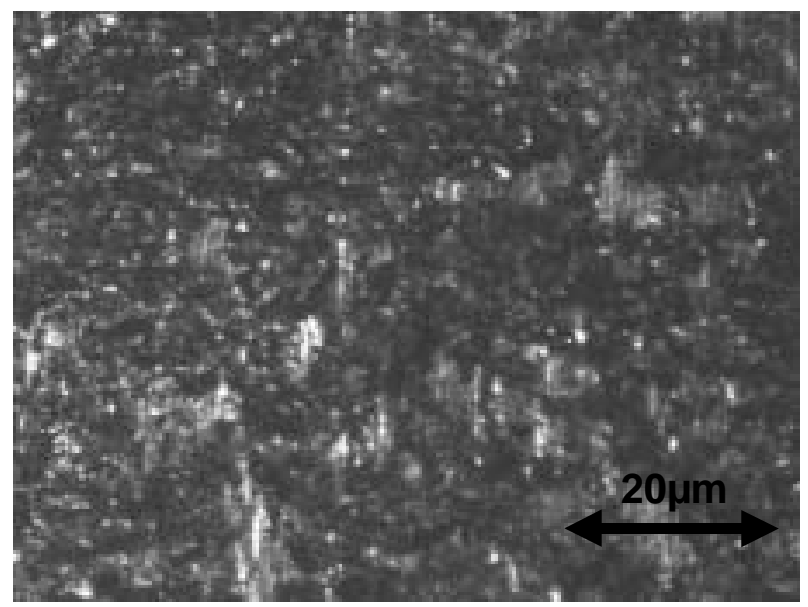

Phoscoating - Metaldyne

Figure 28. Optical Micrographs After Tests in the Lower Cups (AISI 1038)

\section{Acheson}



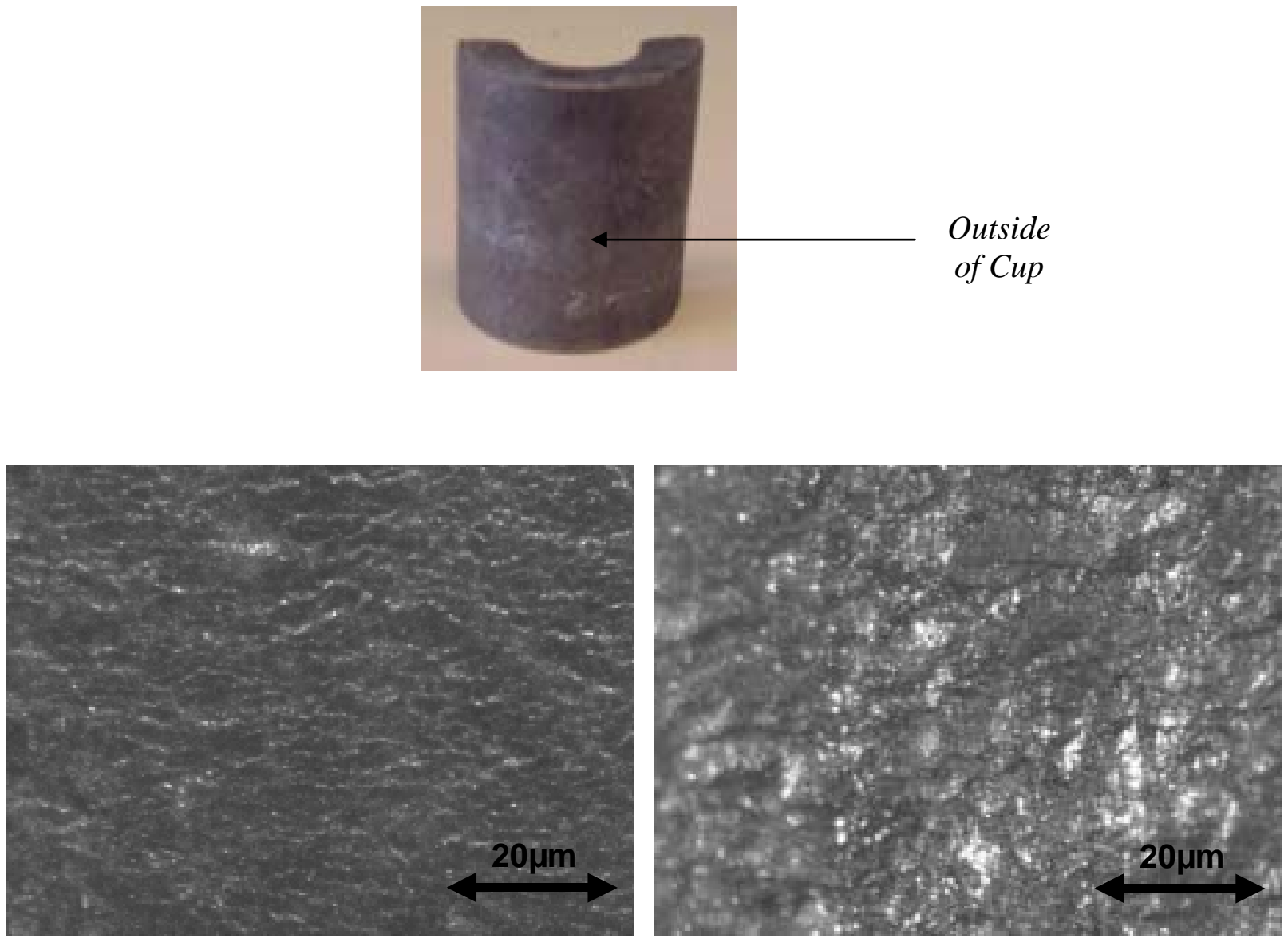

Phoscoating - Metaldyne

Acheson

Figure 29. Optical Micrographs After Tests at the Outside Surface (AISI 1038)

\section{Application of Lubricants}

Two different types of lubricants were applied to the billets before testing:

1. Phosphate coated and soaped provided by Mascotech - Color: Metallic grey. These blanks had uniform coating over the entire surface. The weight of phosphate and soap are unknown.

2. Acheson-France coated using proprietary Acheson coating - Color: Silver black. These blanks appeared to be sprayed or dipped in the coating media. The coating was not uniform. A majority of the billets had thick coat rims around the ends and they did not fit the container. To resolve the problem, all Acheson coated billets were chamfered on both ends using $.015 \times 45$-degree chamfers. Still, some of the blanks with thicker coating on the ends did not fit in the tooling so they had to be hand selected and checked prior to forming.

It should be noted that the ERC/NSM also tested and compared the Acheson lubricant to a phoscoating.

\section{Experimental Setup}

An RP-48 converted radial press with extrusion capability was used for the tests. Figure 30 
shows this equipment. Figure 31 shows the double cup backward extrusion tooling. Table 11 summarizes the materials used in the construction of this tooling. Two punch coatings were used in the tests:

- Two punches supplied by Kinefac were titanium nitrate (TiN) coated by Balzers

- Two punches supplied by Delphi were coated by a multi-coat process called hard lube (TiAlN + WCC).

Instrumentation was supplied by Sensing Systems Company. It was custom designed to fit the RP-48 envelope. Two load cells were included: one mounted under the bottom punch and container and the second above the top punch (Figure 31). Data was collected using a notebook computer, a 16-bit PCMCIA data acquisition interface, a signal conditioning unit and Winview software.

\section{Tests}

The double cup backward extrusion tests were completed at Kinefac Corporation using the RP48 converted radial press. Tests were conducted at four different stroke lengths. Table 12 shows the experimental matrix used by Kinefac Corporation.

\section{Results and Discussion}

In evaluating the cup height ratios, $\mathrm{R}_{\mathrm{ch}}=\mathrm{H}_{1} / \mathrm{H}_{2}$, the average of 25 samples was taken..

\section{Performance of Phoscoating with TiN Punch Coatings}

The average cup height ratios, $\mathrm{H}_{1} / \mathrm{H}_{2}$, for the phoscoating tests with TiN punch coatings were

Table 11. Double Cup Backward Extrusion Tooling Materials

\begin{tabular}{|c|c|c|c|}
\cline { 2 - 4 } \multicolumn{1}{c|}{} & Punch & Container & Die Housing \\
\hline \multirow{4}{*}{ Material } & Impact Grade & Micro-Grain & H-13, \\
& GC-G50 & GC-015 & $46-48$ HRC \\
& (C-13) Carbide & Carbide & \\
\hline
\end{tabular}

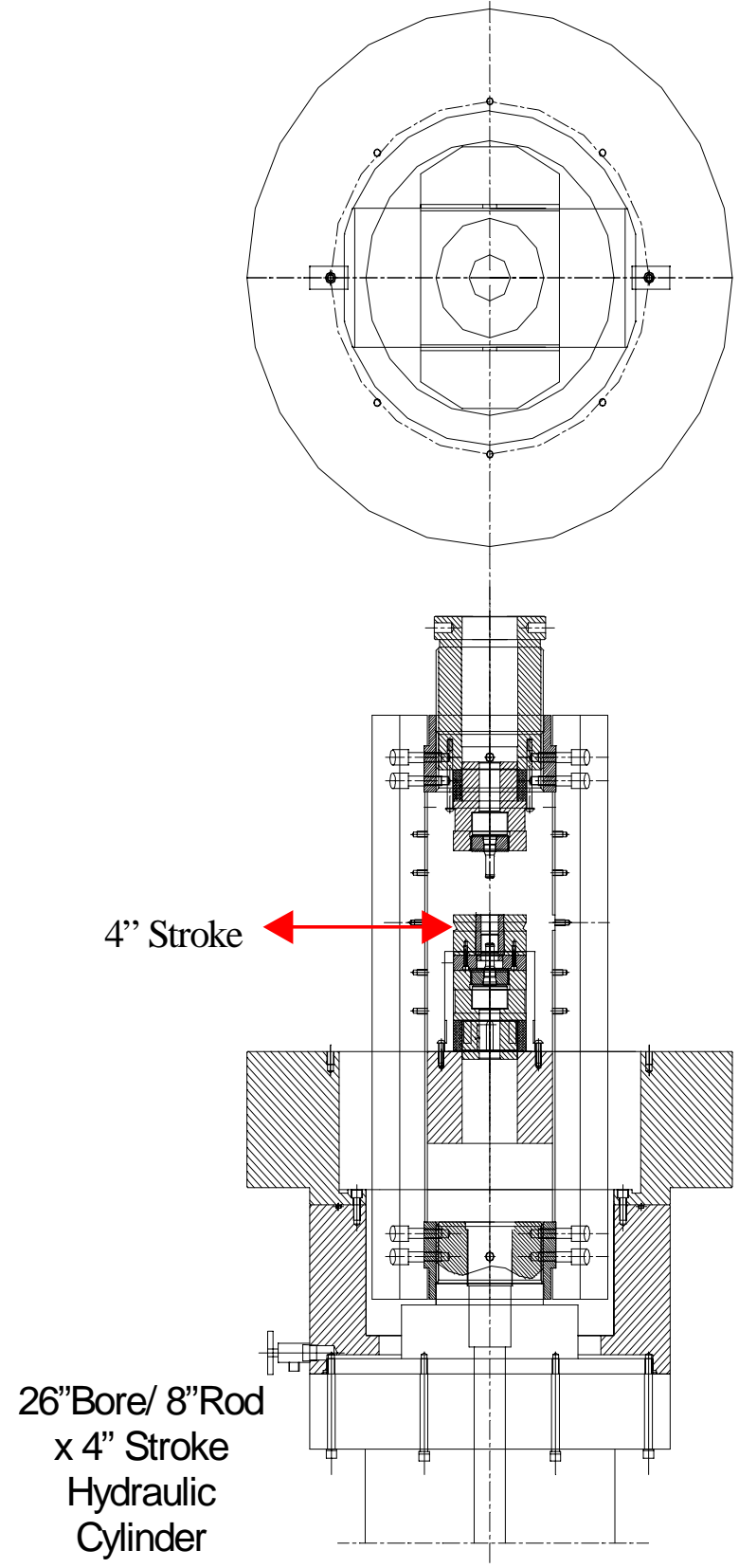

Figure 30. RP-48 Converted Radial Press with Extrusion Capability

measured to be $2.48,2.32$, and 2.21. In addition, the average real strokes were 12.09, 15.35, and $18.54 \mathrm{~mm}$. By plotting these values on the friction factor calibration curve, the average friction factors for this lubricant at the three different stroke lengths were estimated to be $\mathrm{m}=0.060, \mathrm{~m}=0.060$, and $\mathrm{m}=0.065$ respectively (Figures 32 - 34). In addition, the ranges were $\mathrm{m}=0.055$ to $\mathrm{m}=0.065, \mathrm{~m}=0.050$ to $\mathrm{m}=0.065$, and $\mathrm{m}=0.050$ to 0.070 respectively. 


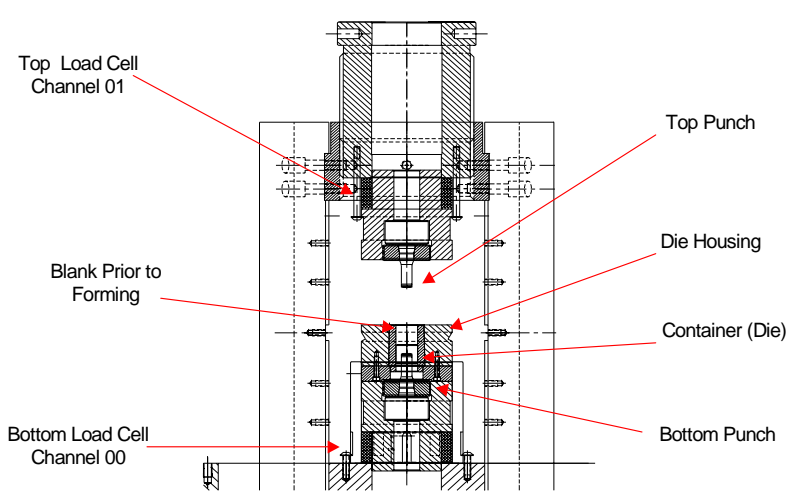

Figure 31. Double Cup Backward Extrusion Tooling

\section{Performance of Acheson Lubricant with TiN Punch Coatings}

The average cup height ratios, $\mathrm{H}_{1} / \mathrm{H}_{2}$, for the Acheson lubricant tests with TiN punch coatings were measured to be $2.75,2.77$, and 2.49 . In addition, the average real strokes were 11.95 $\mathrm{mm}, 15.14$, and $19.43 \mathrm{~mm}$. By plotting these values on the friction factor calibration curve, the average friction factors for this lubricant at the three different stroke lengths were estimated to be $\mathrm{m}=0.070, \mathrm{~m}=0.080$, and $\mathrm{m}=0.075$ respectively (Figures 35 - 37). In addition, the ranges were $\mathrm{m}=0.065$ to $\mathrm{m}=0.075, \mathrm{~m}=0.075$ to $\mathrm{m}=0.085$, and $\mathrm{m}=0.050$ to $\mathrm{m}=0.085$ respectively.

\section{Performance of Phoscoating with TiAIN + WCC Punch Coatings}

The average cup height ratio, $\mathrm{H}_{1} / \mathrm{H}_{2}$, for the phoscoating tests with TiAlN + WCC punch

Table 12. Experimental Matrix Used by Kinefac Corporation

\begin{tabular}{|c|c|c|c|c|}
\hline Stroke & Lubricant & $\begin{array}{c}\text { Billet } \\
\text { Material }\end{array}$ & $\begin{array}{c}\text { Punch } \\
\text { Coating }\end{array}$ & $\begin{array}{c}\text { No. of } \\
\text { Specimens }\end{array}$ \\
\hline $12 \mathrm{~mm}$ & Phoscoating & AISI 1038 & TiN & 25 \\
\hline $12 \mathrm{~mm}$ & Acheson & AISI 1038 & TiN & 25 \\
\hline $15 \mathrm{~mm}$ & Phoscoating & AISI 1038 & TiN & 25 \\
\hline $15 \mathrm{~mm}$ & Acheson & AISI 1038 & TiN & 25 \\
\hline $19 \mathrm{~mm}$ & Phoscoating & AISI 1038 & TiN & 25 \\
\hline $19 \mathrm{~mm}$ & Acheson & AISI 1038 & TiN & 25 \\
\hline $21 \mathrm{~mm}$ & Phoscoating & AISI 1038 & $\begin{array}{c}\text { TiAIN }+ \\
\text { WCC }\end{array}$ & 25 \\
\hline $21 \mathrm{~mm}$ & Acheson & AISI 1038 & $\begin{array}{c}\text { TiAIN }+ \\
\text { WCC }\end{array}$ & 25 \\
\hline
\end{tabular}

coatings was measured to be 2.12 . In addition, the average real stroke was $20.81 \mathrm{~mm}$. By plotting these values on the friction factor calibration curve, the average friction factor for this lubricant was estimated to be $\mathrm{m}=0.065$ while the range was $m=0.055$ to 0.070 (Figure 38 ).

\section{Performance of Acheson Lubricant with TiAIN + WCC Punch Coating}

The average cup height ratio, $\mathrm{H}_{1} / \mathrm{H}_{2}$, for the Acheson lubricant tests with TiAlN + WCC punch coating was measured to be 2.34 . In addition, the average real stroke was $21.19 \mathrm{~mm}$. By plotting these values on the friction factor calibration curve, the average friction factor for this lubricant was estimated to be $\mathrm{m}=.075$ while the range was 0.055 to 0.085 (Figure 39).

\section{Performance Comparison of Lubricants and Punch Coatings}

Nearly the same forming load was experienced for all tests. Therefore, the load cannot be used to evaluate the performance of the lubricants.

To establish a ranking of the lubricants, lubricant performance diagrams were made. With these diagrams, the cup height ratios, $\mathbf{R}_{\mathrm{ch}}$, are plotted on the ordinate and the friction factor is plotted on the abscissa. The value of the cup height ratio is read from the lower position of the data range, whereas the value of the friction factor is read from the upper position of each data range. It should be noted that these values are an average from the 25 samples. The aim of a successful double cup extrusion operation is to reach processes with a minimum cup height ratio at a minimum friction factor. Therefore, in this diagram, the lubricant with the best performance is located closest to the origin.

In Figures $40-42$, the lubricant performance diagrams for stroke lengths of 12,15 , and 19 $\mathrm{mm}$ respectively are shown. It should be noted that these tests were conducted with TiN coated punches. In Figure 43 the lubricant performance diagram for a stroke length of $21 \mathrm{~mm}$ is shown. 
It should be noted that these tests were conducted with TiAlN + WCC coated punches. The figures show that the phoscoating performs better than the Acheson lubricant at all stroke lengths. The average cup height ratio from experiments conducted with the Acheson lubricant is $15 \%$ higher than the experiments con- ducted with phoscoating. Also, the friction factor increases by an average of $20 \%$. Recall that the ERC/NSM obtained the same result for a stroke length of $21 \mathrm{~mm}$. It should also be noted that no significant change is noted between the TiN coated punches and the TiAlN + WCC coated punches (Figures 42 and 43).

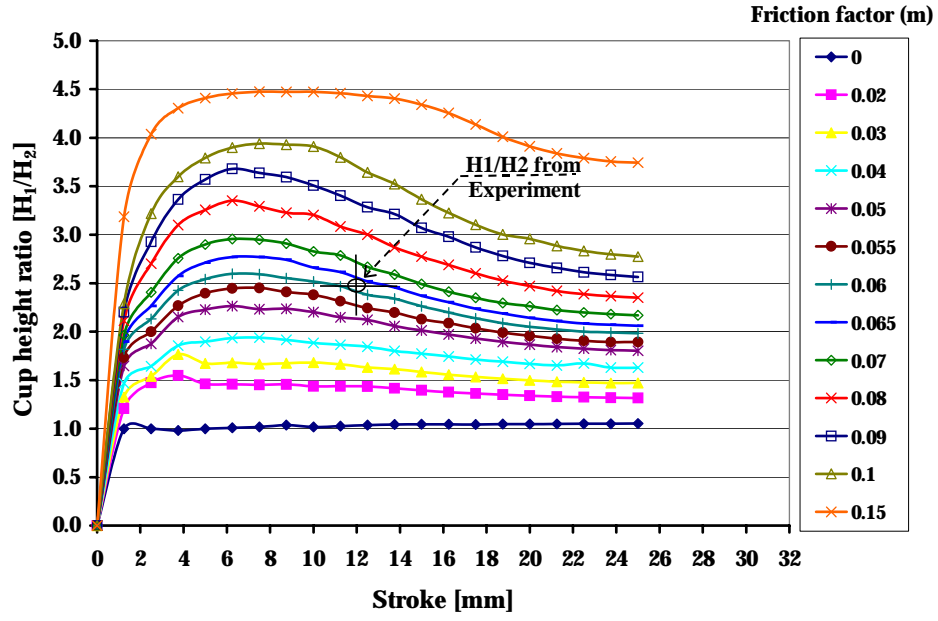

Figure 32. Phoscoating: Determination of Friction Factor Value $\mathbf{m}$ (Stroke = $12 \mathrm{~mm}$ )

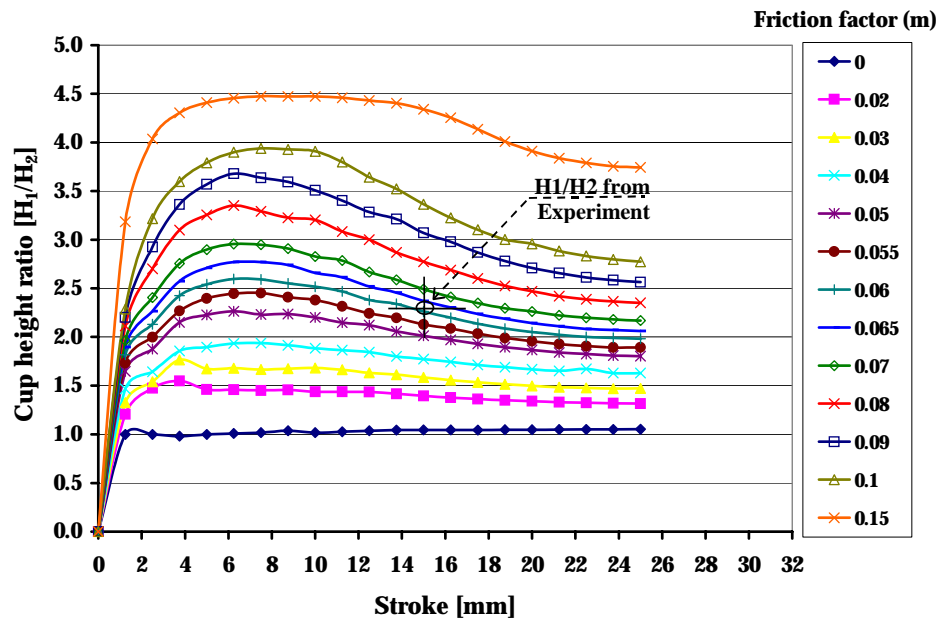

Figure 33. Phoscoating: Determination of Friction Factor Value $\mathbf{m}$ (Stroke $=15 \mathrm{~mm}$ ) 


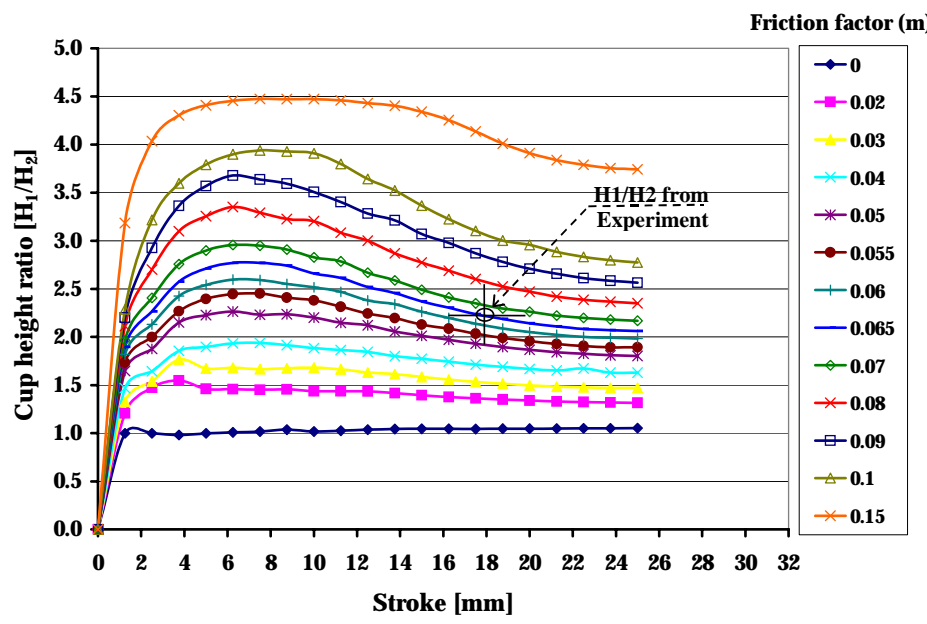

Figure 34. Phoscoating: Determination of Friction Factor Value $\mathbf{m}$ (Stroke $=19 \mathrm{~mm}$ )

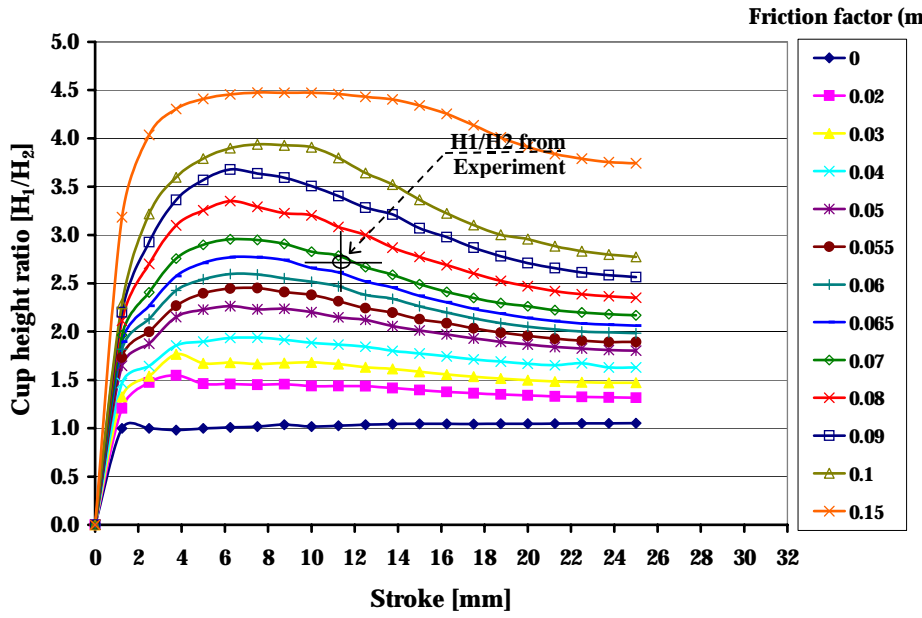

Figure 35. Acheson Lubricant: Determination of Friction Factor Value $\mathbf{m}$ (Stroke $=12 \mathrm{~mm}$ )

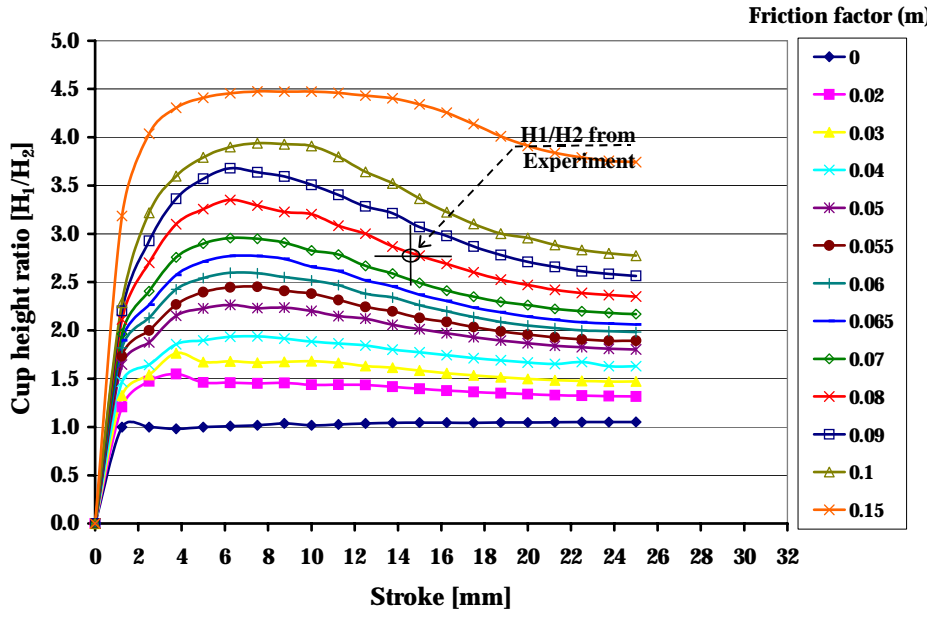

Figure 36. Acheson Lubricant: Determination of Friction Factor Value $\mathrm{m}$ (Stroke $=15 \mathrm{~mm}$ ) 


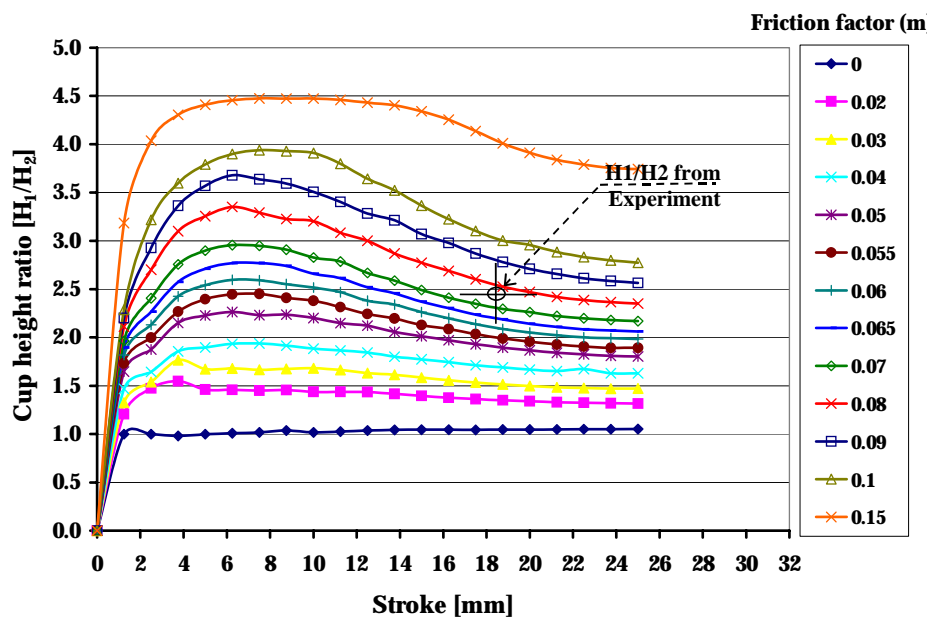

Figure 37. Acheson Lubricant: Determination of Friction Factor Value $\mathbf{m}$ (Stroke $=19 \mathrm{~mm}$ )

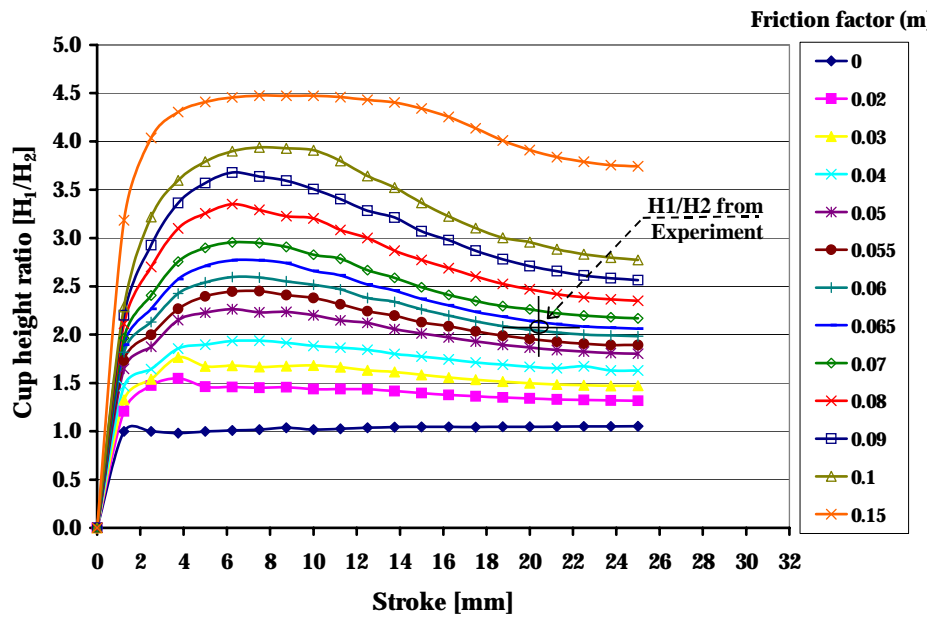

Figure 38. Phoscoating: Determination of Friction Factor Value $\mathbf{m}$ (Stroke $=21 \mathrm{~mm}$ )

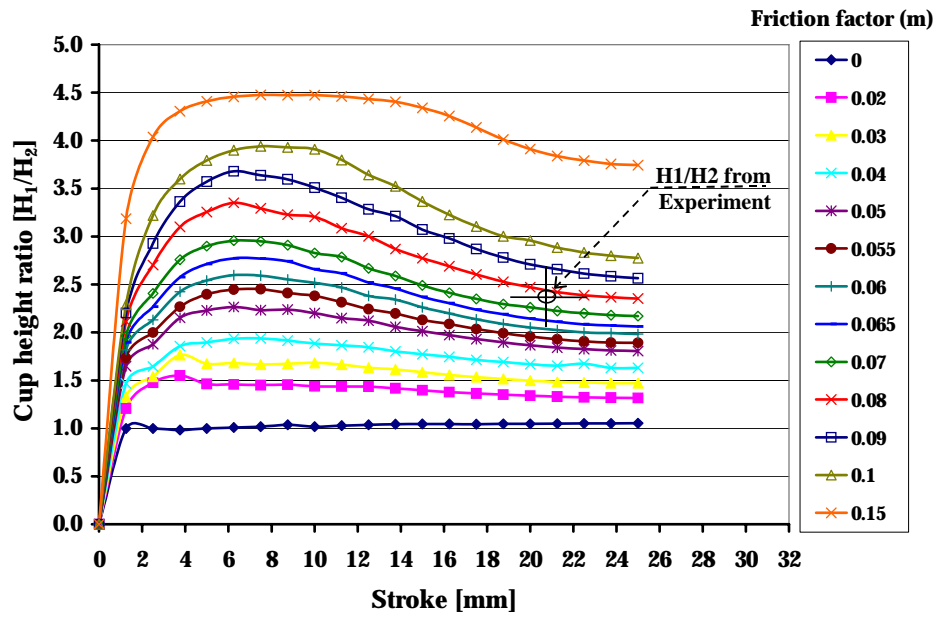

Figure 39. Acheson Lubricant: Determination of Friction Factor Value $\mathbf{m}$ (Stroke $=21 \mathrm{~mm}$ ) 


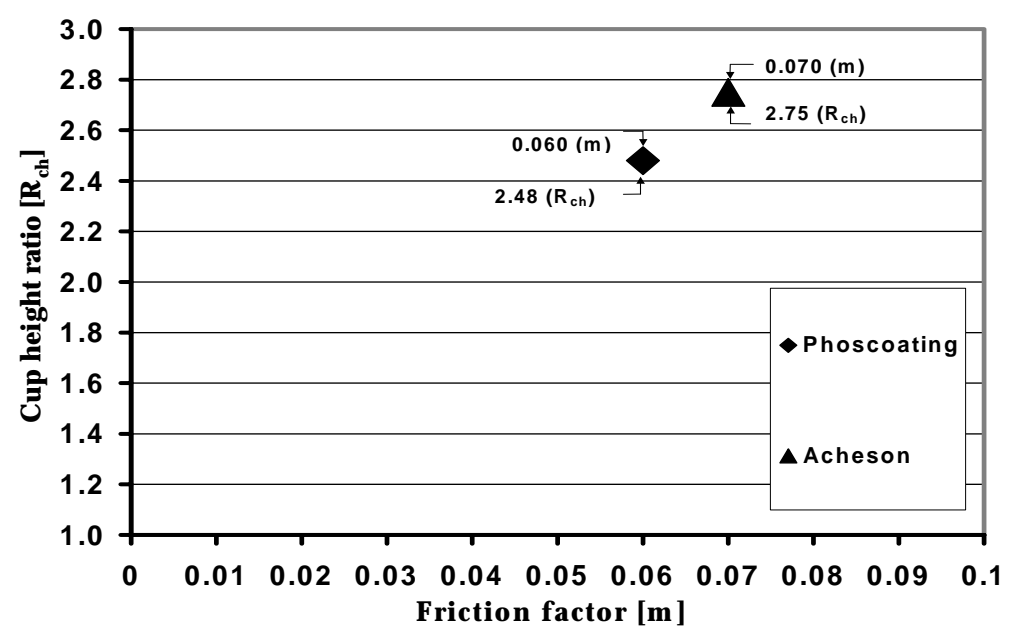

Figure 40. Lubricant Performance as a Function of Cup Height Ratio and Friction Factor (12 mm Stroke and TiN Coated Punches)

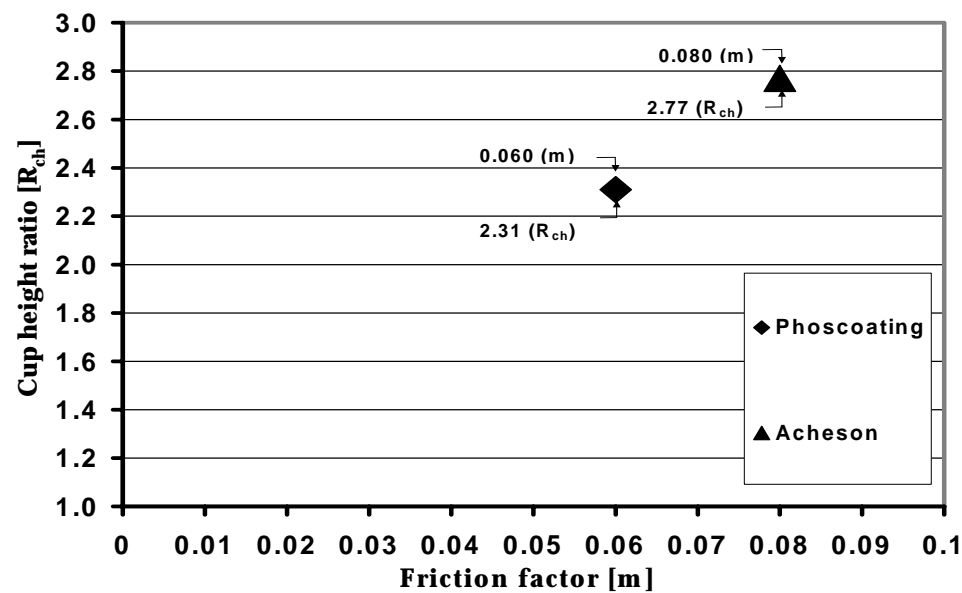

Figure 41. Lubricant Performance as a Function of Cup Height Ratio and Friction Factor (15 mm Stroke and TiN Coated Punches)

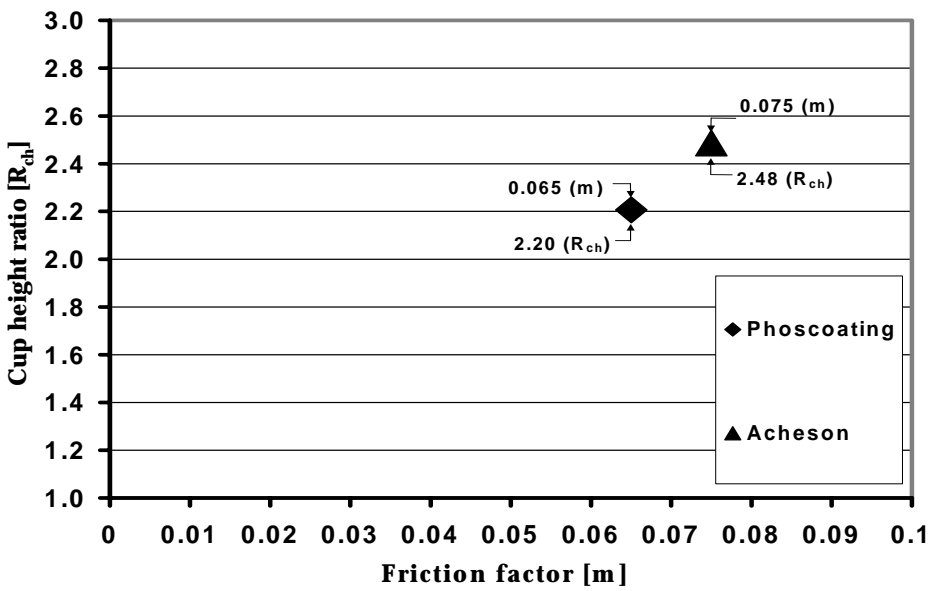

Figure 42. Lubricant Performance as a Function of Cup Height Ratio and Friction Factor (19 $\mathrm{mm}$ Stroke and TiN Coated Punches) 


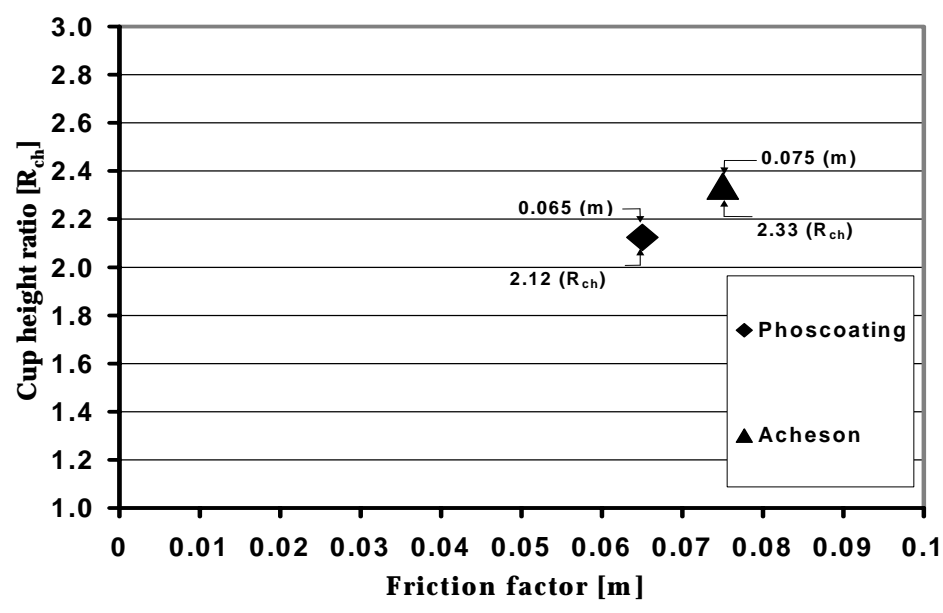

Figure 43. Lubricant Performance as a Function of Cup Height Ratio and Friction Factor $(21 \mathrm{~mm}$ Stroke and TiAIN + WCC Coated Punches)

Figure 44 shows the friction factor for the various stroke lengths and lubricants in bar graph form. The figure shows that the average friction factor increases as the stroke increases from 12 to $15 \mathrm{~mm}$ for the Acheson lubricant while the friction factor remains nearly constant with increasing stroke for phoscoating. It should also be noted that the friction factor range increases dramatically for stroke lengths of 19 and $21 \mathrm{~mm}$ for the Acheson lubricant. Finally, it should be noted that no significant change is noted between the TiN coated punches used at a stroke of $19 \mathrm{~mm}$ and the TiAlN + WCC coated punches used at a stroke length of $21 \mathrm{~mm}$.

As shown in Figure 45, a large range of cup height ratios was observed with the Acheson lubricant as compared to phoscoating. This indicates a large variation in the parameters affecting friction for the Acheson lubricant tests. Like the ERC/NSM, the Kinefac Corporation noted the Acheson lubricant was not evenly coated on the billets. This may have been the cause of the large cup height ratio variation observed in Figure 45.

\section{Conclusions}

The following conclusions were made from the tests conducted at the Kinefac Corporation:

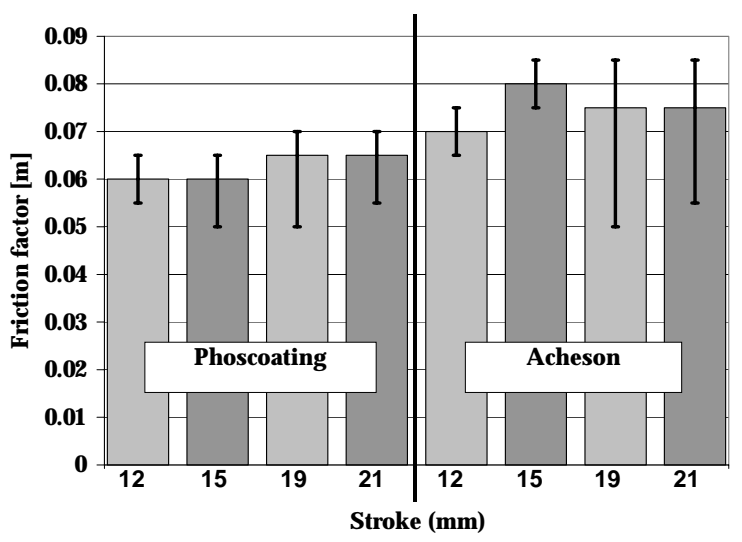

Figure 44. Friction Factor for Various Stroke Lengths and Lubricants

- Phoscoating performed better than the Acheson lubricant. The average friction factor for phoscoating was $\mathrm{m}=0.065$ for all test conditions and the average friction factor for the Acheson lubricant was $\mathrm{m}=0.075$ for all test conditions.

- The trials were not showing any significant change in the forming forces regardless of type of billet or punch coating.

- A more detailed analysis of the numerical data may indicate small advantages of one coating over another. 


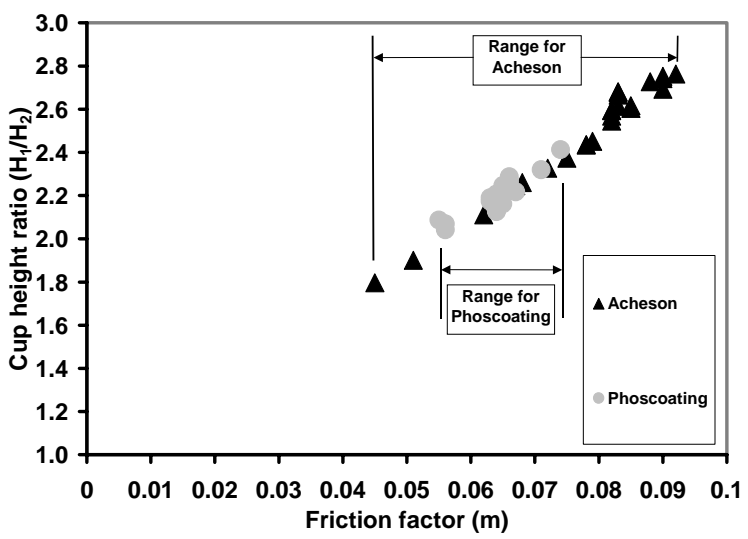

Figure 45. Performance Comparison for Acheson and Phoscoating Lubricants (19 mm Stroke)

- A long term study based on larger production runs is needed to determine the effectiveness of the Acheson coating and its effects on quality of formed parts and die/punch life.

- The coating application process used by Acheson should be improved to assure uniform and consistent coating thickness. The lack of consistency may lead to problems during loading the die nests and cause potential tooling damage.

- The punches and the container did not show any signs of galling or pickup.

\section{Summary and Concluding Remarks}

Presently, most cold forging processes require a zinc phosphate based lubricant; however, there are numerous problems with this lubrication system. These problems include: hazardous waste disposal, high equipment and energy costs, and human health risks. Therefore, research worldwide is focused on developing environmentally friendly cold forging lubricants.

The double cup backward extrusion test is used extensively for evaluating lubricants in cold forging. It can be used to find the friction factor of lubricants and thereby serves as a good tool for ranking various lubricants. The high surface expansion during the test simulates the actual forging process more closely than other such tests.

The following tasks were accomplished during the course of this project:

- A test apparatus for evaluating lubricants by the double cup backward extrusion test was built.

- A survey of environmentally friendly cold forging lubricants was completed. Four companies, include MEC, Daido, Acheson and MCI, were identified as companies which manufactured potential lubricants for the replacement of zinc phosphate in cold forging.

- The material properties (flow stress) of two materials were determined by compression tests.

- The ideal stroke for the double cup backward extrusion test was determined in order to obtain cup heights that reduced the probability of measurement error while averting the formation of cracks in the outer billet surface.

- Double cup backward extrusion tests were conducted using M2 tool steel punches with each of the lubricants. The friction factor of each lubricant was determined by using calibration curves. These calibration curves were obtained using finite element simulations.

The lubricants were not evaluated based on the ease of removal from the billet material. Also, change in properties of the base material after the use of these lubricants has not been studied. A chemical analysis of the surface and the use of these lubricants in production runs will reveal the performance of the lubricants with respect to these factors.

In order to further evaluate the Acheson lubricant as compared to phoscoating, a series of double cup backward extrusion tests were 
conducted at the Kinefac Corporation. The billets were cut from the same AISI 1038 stock as the billets used by the ERC/NSM. The geometry of the forming tooling was identical to that developed at the ERC/NSM; however, the punches were made from carbide as opposed to M2 tool steel. In addition, the Kinefac Corporation was able to incorporate two punch coatings, namely TiN and TiAlN + WCC, into their tests. 


\section{References}

[Altan, et al. 1992]

Buschhausen, A., Lee, J. Y., Weinmann, K. and Altan, T., "Evaluation of Lubrication and Friction in Cold Forging Using a Double Backward Extrusion Process," Journal of Materials Processing Technology, 1992, Vol. 33 (1-2), pp. 95-108.

[Barcellona, et al. 1996] Barcellona, A., Canizzaro, L., "Validation of Friction Studies by Double Cup Extrusion Tests in Cold Forming," Annals of the Cirp, 1996, Vol. 45 (1) pp. 211-214.

[Bay, 1994]

Bay, N., "The State-of-the-Art in Cold Forging Lubrication," Journal of Materials Processing Technology, 1994, Vol. 46, pp. 19-40.

[Forcellese, et al. 1994]

Forcellese, A., Gabrielli, F., Barcellona, A., Micari, F., "Evaluation of Friction in Cold Metal Forming," Journal of Materials Processing Technology, 1994, Vol. 45, pp. 619-624.

[Schmoeckel, et al. 1997]

Schmoeckel, D., Rupp, M., ’Umweltfreundlichere Kaltmassivumformung - Fertigung von Draht ohne Zinkphosphatschicht," Vortragstexte des Symposiums "Neuere Entwicklungen in der Massivumformung", Fellbach bei Stuttgart, 1997, pp. 183-200.

[Wenning, et al. 2002]

Wenning, P., Gracious, N. and Altan, T., "Overview of National Instruments SCXI Data Acquisition System: SCXI-1520 8-Channel Strain Gauge Module \& SCXI-1112 8-Channel Thermocouple Module," ERC Report in preparation. 